Issued by Sandia National Laboratories, operated for the United States Department of Energy by Sandia Corporation.

NOTICE: This report was prepared as an account of work sponsored by an agency of the United States Government. Neither the United States Government, nor any agency thereof, nor any of their employees, nor any of their contractors, subcontractors, or their employees, make any warranty, express or implied, or assume any legal liability or responsibility for the accuracy, completeness, or usefulness of any information, apparatus, product, or process disclosed, or represent that its use would not infringe privately owned rights. Reference herein to any specific commercial product, process, or service by trade name, trademark, manufacturer, or otherwise, does not necessarily constitute or imply its endorsement, recommendation, or favoring by the United States Government, any agency thereof, or any of their contractors or subcontractors. The views and opinions expressed herein do not necessarily state or reflect those of the United States Government, any agency thereof, or any of their contractors.

Printed in the United States of America. This report has been reproduced directly from the best available copy.

Available to DOE and DOE contractors from Office of Scientific and Technical Information

P.O. Box 62

Oak Ridge, TN 37831

Prices available from (703) 605-6000

Web site: http:/www.ntis.gov/ordering.htm

Available to the public from

National Technical Information Service

U.S. Department of Commerce

5285 Port Royal Rd

Springfield, VA 22161

NTIS price codes

Printed copy: A03

Microfiche copy: A01

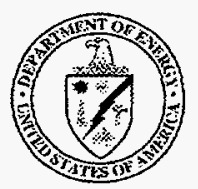




\section{DISCLAIMER}

Portions of this document may be illegible in electronic image products. Images are produced from the best available original document. 
SAND 98-2421

Unlimited Release

Printed January 1999

\title{
Technique For Measuring Hybrid Electronic Component Reliability
}

\author{
Cynthia L. Hernandez \\ F. Michael Hosking \\ Materials Joining Department \\ David Robinson \\ Systems Reliability Department \\ Brian Rutherford \\ Statistics and Human Factors Department \\ Christopher C. Green \\ Advanced Devices and Applications Department \\ Fernando Uribe \\ Thin Film, Vacuum and Packaging Department \\ Sandia National Laboratories \\ P.O. Box 5800 \\ Albuquerque, NM 87185-1411
}

\begin{abstract}
Materials compatibility studies of aged, engineered materials and hardware are critical to understanding and predicting component reliability, particularly for systems with extended stockpile life requirements. Nondestructive testing capabilities for component reliability would significantly enhance lifetime predictions. For example, if the detection of crack propagation through a solder joint can be demonstrated, this technique could be used to develop baseline information to statistically determine solder joint lifelengths. This report will investigate high frequency signal response techniques for nondestructively evaluating the electrical behavior of thick film hybrid transmission lines.
\end{abstract}




\section{ACKNOWLEDGMENTS}

This work was performed by Sandia National Laboratories, in collaboration with Hampton University. The authors would like to acknowledge the support Professors Ganiyu Hanidu*, Mohammed Rachedine* and Adebisi O. Oladipupo of the Electrical Engineering Department at Hampton University for their help with the computational simulations. Several students from Hampton University contributed to this project, in particular, Lareina Adams, who completed a student internship at Sandia during the summer of 1997. The authors also acknowledge Ken Holley, Education Outreach Department; Charlie Sandoval, Advanced Devices and Applications Department; and Gary Zender and Bonnie McKenzie of the Microstructural Analysis Department at Sandia National Laboratories. Special thanks to Dick Salzbrenner and Kay Hays of Sandia National Laboratories for their programmatic support.

The manuscript was reviewed by Ed Lopez.

${ }^{*}$ Currently at Motorola, Inc. Applied Simulation and Modeling Research; Schaumburg, IL. 


\section{CONTENTS}

Acknowledgments $\quad$................................................. 2

Table of Contents $\quad$................................................. 3

Background ........................................................... 4

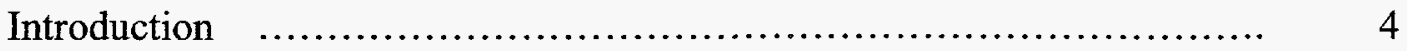

Materials and Test Procedure ......................................... 5

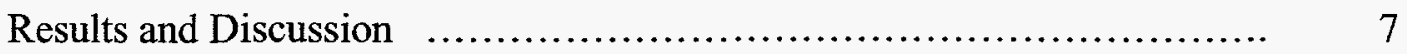

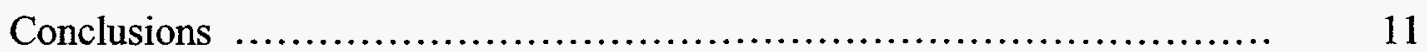

References .......................................................... 11

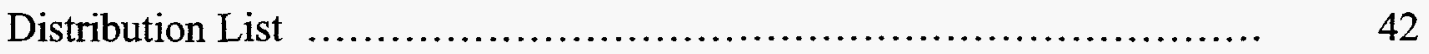

\section{FIGURES}

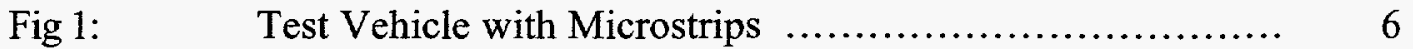

Fig 2: $\quad$ SEM transverse images of Nd:YAG laser test cuts ........... 7

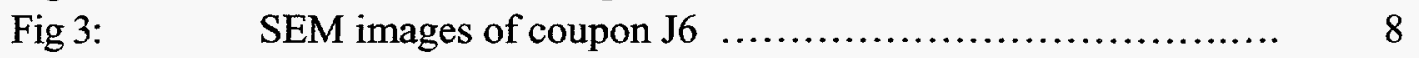

Fig 4: $\quad$ S-parameter reflection and transmission data for coupon J6 $\quad \ldots \quad 12$

Fig 5: $\quad$ Computer simulation data for coupon J6 ................... 16

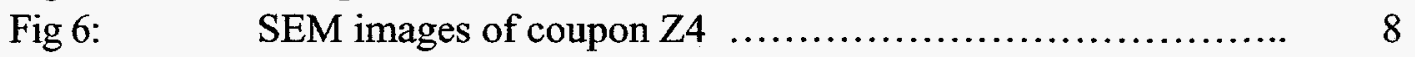

Fig 7: $\quad$ S-parameter reflection and transmission data for coupon Z4 .. $\quad 18$

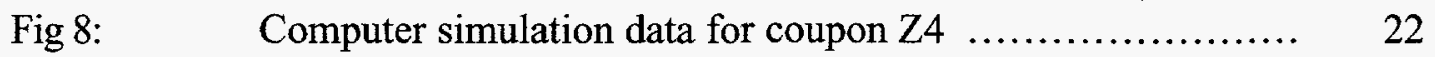

Fig 9: $\quad$ SEM images of coupon Y4 ............................ 9

Fig 10: $\quad$ S-parameter reflection and transmission data for coupon Y4 ... 24

Fig 11: $\quad$ Computer simulation data for coupon Y4 .................... 28

Fig 12: $\quad$ SEM images of coupon $\mathrm{C} 1$............................... 9

Fig 13: $\quad$ S-parameter reflection and transmission data for coupon $\mathrm{C} 1 \ldots . \quad 30$

Fig 14: $\quad$ S-parameter reflection and transmission data for coupon E1 $\quad \ldots \quad 34$

Fig 15: $\quad$ SEM images of coupon S1 ................................ 10

Fig 16: $\quad$ S-parameter reflection and transmission data for coupon S1 ... 38 


\section{BACKGROUND}

Sandia National Laboratories and Hampton University collaborated on a research project designed to address aging of components in the nuclear weapons stockpile. The two year program had two goals: 1) to develop a reliable analysis method for evaluating component reliability and: 2) the accreditation of Hampton University as a graduate institution for Engineering Sciences.

\section{INTRODUCTION}

Aging studies of engineered materials, components, and sophisticated systems have historically been an important part of materials compatibility and reliability studies. The analysis technique most often used, Arrhenius analysis, is well known and dates back to the late 1800's. The method requires experimental characterization of isothermal rates of degradation processes at prechosen temperatures and then plotting the isothermal rates versus reciprocal absolute temperature to obtain an activation energy for each degradation reaction. These activation energies can then be utilized to predict the component lifetime at useful temperatures other than those chosen for the experiment.

The use of impedance techniques to characterize materials properties is also widespread and well documented [1]. They consist of the application of a small signal voltage of varying AC frequency to a given material through suitable electrodes. The resulting current flow is then measured and the impedance determined as the ratio of the applied voltage to the measured current at each frequency.

The recent introduction of the Stockpile Life Extension Program has made it clear that electronic circuits will be exposed to ever-increasing influence of random storage and use environments. This has generated a need to develop a new methodology for characterizing the reliability of systems. Reliable behavior of microelectronic systems in random environments is largely determined by thermo-mechanical properties of both circuit components and associated interconnections. Solder joints are one of the most common types of interconnections in these systems. However, solder joints in electronic packages have been known to fail prematurely and unexpectedly due to continued aging in thermal environments. For example, fluctuations in temperature might arise during transportation of weapon systems from one environment to another and may be cause for the failure. Thermal excursions can cause dimensional changes in the materials used to fabricate circuits and these changes induce damage in the solder. Moreover, heterogeneous and irreversible damage occurs in solder due to the constraints imposed by the more rigid surrounding materials. In addition to variability in the external environment, significant residual stresses remain in the solder connections as a result of the manufacturing process as well as methods used for preparation of the components to be used in the assembly (e.g., pre-tinning of component leads). It is, however, difficult to incorporate time dependent material properties and variations in the manufacturing 
process and the operational environment. These stresses alone can instigate significant changes in the microstructure of the solder. New failure information, both experimental as well as field data, is constantly being generated on similar or even identical electronic systems.

In addition to the Arrhenius method, there are a number of popular methods currently in use for the prediction of the useful life of microelectronic systems. They typically involve extensive computer modeling and simulations. One method involves the prediction of the median fatigue life of a solder connection based upon a complex relationship between coefficients of thermal expansion, temperature cycles and diffusion rates, among many others. A second method is based primarily on the use of constant failure rates for the various elements that constitute the electronic system. These approaches are oriented toward analysis of a single joint. No methodology exists to relate the life-characteristics of the individual elements (components, solder joints, etc.) to the life characteristics of more complex assemblies.

Nondestructive testing capabilities for component reliability would significantly enhance lifetime predictions. This report introduces a new technical approach to detect and measure crack growth in solder joints due to thermal aging or other environmental conditions. It involves both experimental and computational analyses.

\section{MATERIALS AND TEST PROCEDURE}

A high frequency test vehicle, incorporating six microstrips was designed and manufactured to measure defect responses. It is illustrated in Figure 1. The test vehicle is a $96 \%$ alumina substrate, 0.025 " thick. The microstrips have a planar transmission line geometry and are made of thick film $\mathrm{Au}$, air fired at $850^{\circ} \mathrm{C}$ for $10 \mathrm{~min}$. This process results in a final $\mathrm{Au}$ thickness of 0.0007 ". The width of the lines on the test vehicle is 0.025 ", while the horizontal portion of lines 1,2 and 3 are 0.010 ". Thirty test vehicles were evaluated during the study. 


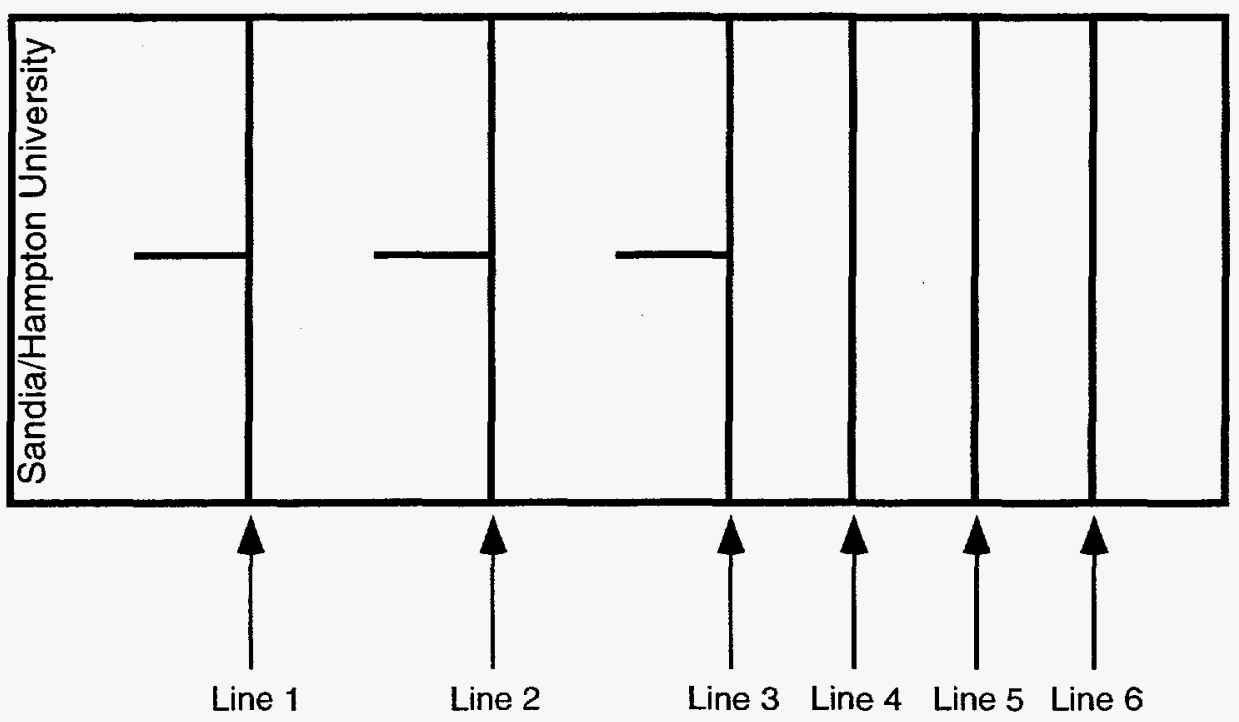

FIGURE 1. Test Vehicle with Microstrips

In order to analyze microwave transmission line problems, it is necessary to identify generalized parameters that represent a typical network. It would be desirable to measure these parameters with reasonable simplicity, even at microwave frequencies. This is achieved by the analysis of the energy flow through a two-port network. The ideal case would be to express a set of parameters when the input and output ports are terminated with their own characteristic impedances at all frequencies. The scattering (s) parameters are the set of parameters that are measured under such conditions. A Hewlett Packard 8510C network analyzer with a Hewlett Packard 8517B scattering-parameter test set was used to analyze the ceramic test coupons. The most critical aspect of the testing, however, is the establishment of a consistent launch at the edges of the test coupon. A change in surface contact due to such things as contamination, surface geometry or alignment of the launch pins can result in unwanted reflections and, hence, changes in the s-parameter measurements. Therefore, before the actual test coupons could be placed in the network analyzer, it was necessary to perform a calibration that de-embeds the line from the test system. This includes removing the effects of the connectors, cables and the transition discontinuity at the launch point. A TRL (Thru Reflect Line) calibration method was used. Standards from a Wiltron 36804B-10M calibration/verification kit were utilized in performing the calibration. After calibration, the phase reference plane was shifted backward from the center of the "thru" line to the launch points. In addition, one of the test coupons was set aside for use as correlation standard to evaluate changes in the Wiltron test fixture after repeated launching. It was measured periodically throughout the test procedure to verify the consistency of the measurements. A $30 \mathrm{ohm}$ Beatty standard from the Wiltron calibration/verification kit was also measured periodically to verify the consistency of the calibration. Calibration drift was virtually 
undetectable throughout the entire test procedure and, thus, the measurements were deemed consistent.

The coupons were placed in a Wiltron $3680 \mathrm{~V}$ test fixture. This test fixture contains two 1.85 mm coaxial connectors with pin launchers that launch to each end of a microstrip line on the test coupon. The two test port cables on the network analyzer connect to the two $1.85 \mathrm{~mm}$ coaxial connectors to complete the setup. The actual test vehicles were now ready for sparameter measurements. Full 2-port scattering parameters were taken during the test. $S_{11}$ and $S_{22}$ are the reflection coefficients while $S_{12}$ and $S_{21}$ are the transmission coefficients. More specifically, $S_{11}$ is the input reflection coefficient of the network while $S_{22}$ is the output reflection coefficient. $S_{21}$ is the forward transmission through the network and $S_{12}$ is the reverse transmission coefficient. The measurement results are presented as magnitude in $\mathrm{dB}$ versus frequency in $\mathrm{GHz}$. One hundred and one (101) data points between $50 \mathrm{MHz}$ and 50 GHz were collected during the test.

Prior to inducing any defects on the test vehicle, baseline transmission and reflection measurements were taken on each line on all thirty substrates. The coupons were then scribed with a laser to artificially induce cracks on the line. To demonstrate feasibility of the laser, several test cuts were made through similar substrates. Scanning electron microscope (SEM) images represent the results shown in Figure 2.
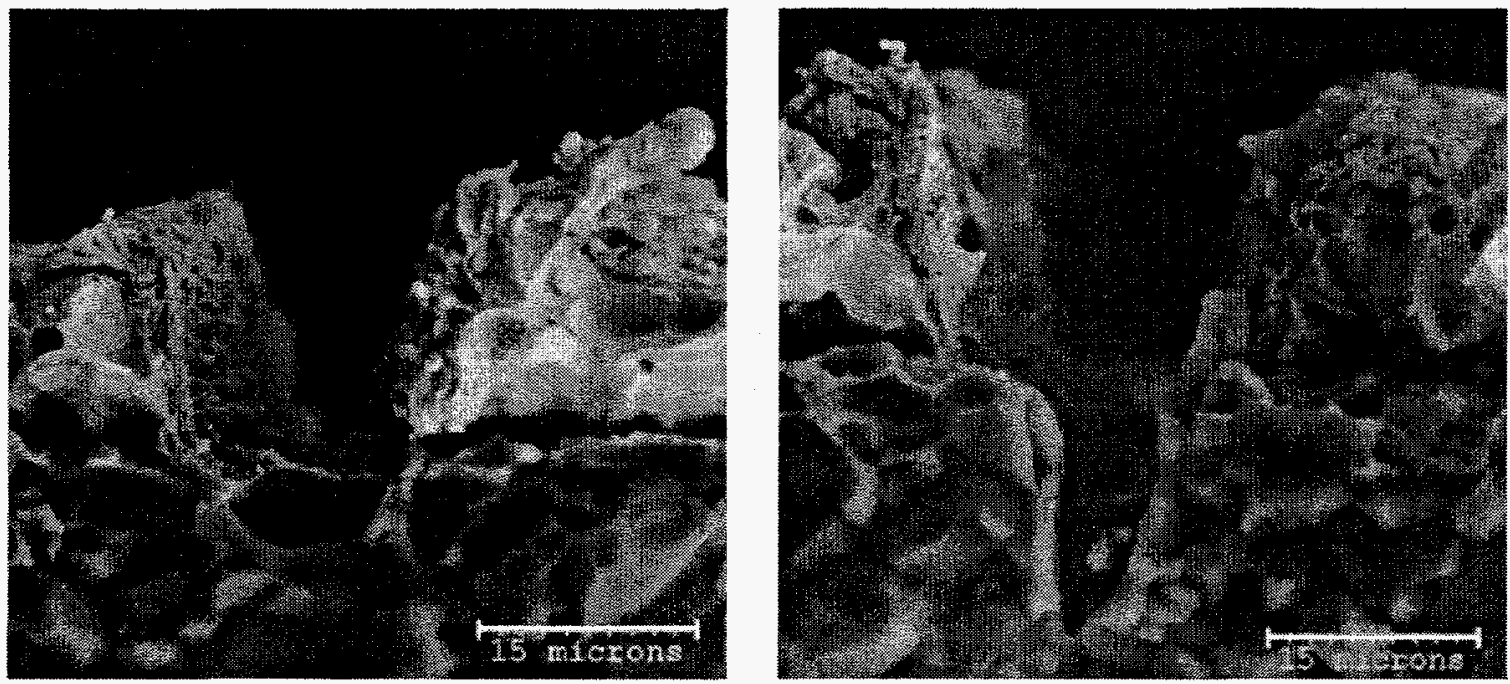

Figure 2. SEM transverse images of Nd:YAG laser test cuts. Laser scribing was performed at a wavelength of $532 \mathrm{~nm}$ and 0.8 watts at a scribe rate of $10 \mathrm{~mm} / \mathrm{sec}$.

The laser scribing procedure was considered uniform, following the initial test cuts. The microstrips were then scribed half way up the notch on the T-lines (lines 1,2 and 3 in Fig. 1) and in the middle of the straight lines (lines 4, 5 and 6). Partial and full cuts were scribed on different lines. The depth of the laser scribing varied from $1 / 2$ to a complete cut through the 
line. The length of the cut across the line also varied. Laser cuts were made $1 / 3,1 / 2,2 / 3$ and all the way across the line. The varying types of defects were induced because it was expected that the measurement data would show that a full cut is far more catastrophic electrically than a partial cut.

\section{RESULTS AND DISCUSSION}

S-parameter measurements from each line on the test coupons were again evaluated on the HP $8510 \mathrm{C}$ network analyzer after laser scribing. Figure 3 shows the SEM micrographs of coupon $\mathrm{J} 6$ after the laser defects were induced. This is a straight line with laser scribing $1 / 2$ deep and $1 / 2$ way across the line.
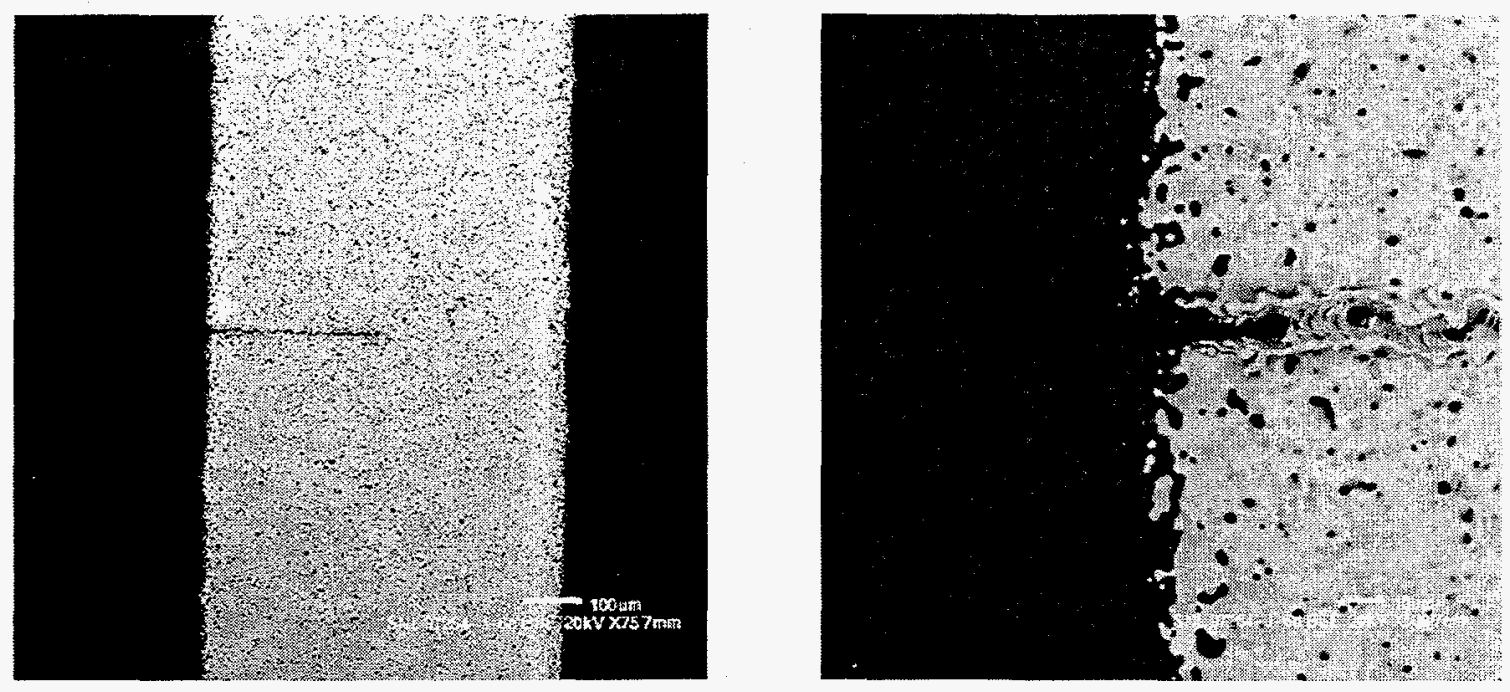

Figure 3. SEM/backscattered emission micrograph of a straight line (coupon J6) after defects have been induced by laser scribing.

S-parameter transmission and reflection data is shown in Fig. 4a-d for coupon J6 before and after defects have been induced. Note how the transmission data is very similar for both $\mathrm{S}_{12}$ and $S_{21}$. There is a slight difference in the reflection data (Fig 4a and b), particularly between 30 and $40 \mathrm{GHz}$. This indicates that greater differences were detected in s-parameter data after defects had been induced.

The measured results were compared to computational models of artificially induced cracks using High Frequency Structure Simulator (HFSS). The method uses a fullwave Maxwell Eminence, a 3D solver to analyze the general algorithm of the random response, its electrical circuit description and mechanical behavior of cracks on a microstrip transmission line. The actual electrical circuit model corresponding to the frequency response obtained from the sparameters validate the insertion loss, the return loss and the center frequency on the line with respect to crack size. These low frequency computer simulations are shown in Figure 5a and $\mathrm{b}$ for coupon $\mathrm{J} 6$. 
In comparison, SEM images are shown below in Fig. 6 for coupon $Z 4$. This was also a straight line with a cut $1 / 3$ of the way across the line and $1 / 2$ depth.
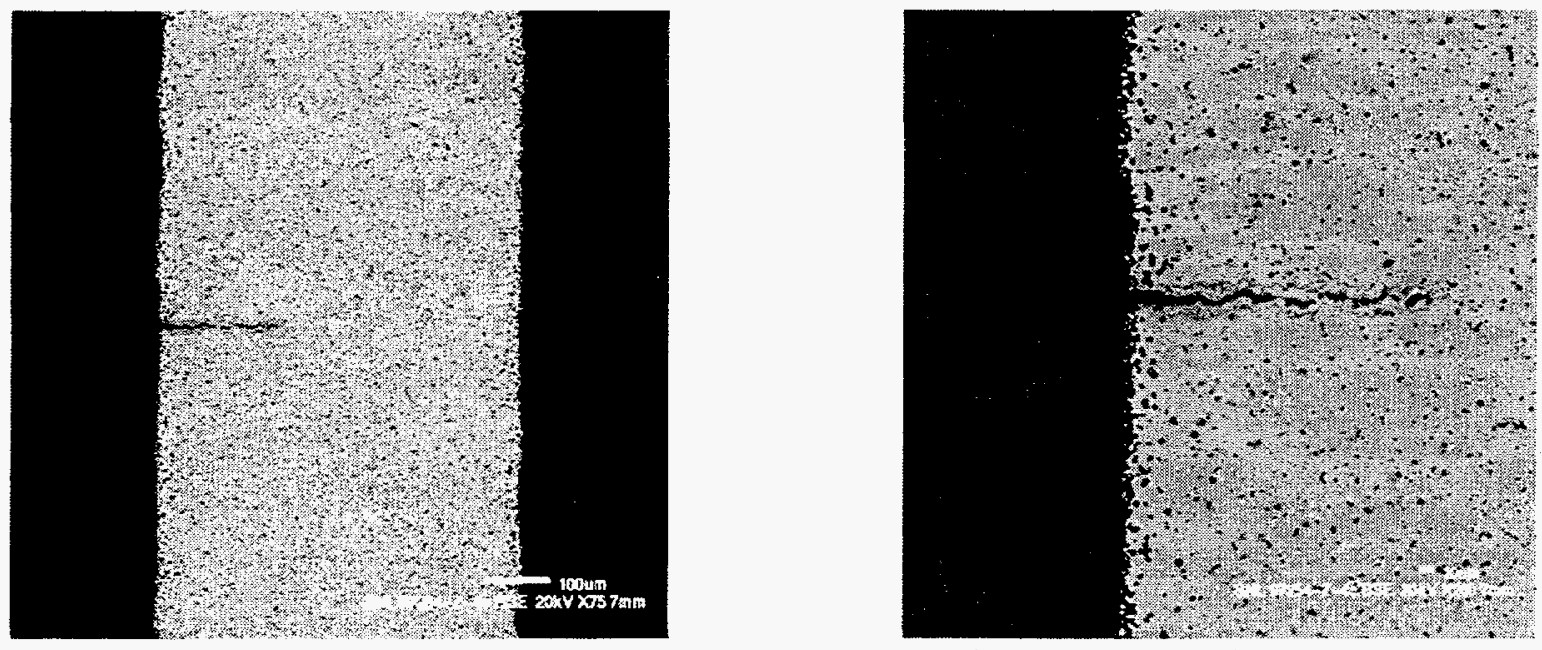

Figure 6. SEM/backscattered emission micrograph of a straight line (coupon Z4) after defects have been induced by laser scribing.

The s-parameter reflection and transmission data is shown in Figure 7a-d for coupon Z4. Once again, the $S_{12}$ and $S_{21}$ transmission data is virtually the same for both sets of measurements. Although the two data sets are similar, more detectable differences are seen at higher frequencies after defects have been induced. There is a slight difference in the $S_{11}$ and $\mathrm{S}_{22}$ reflection data for a $1 / 3$ cut versus a $1 / 2$ cut at all frequencies. Representative low frequency $S_{11}$ and $S_{21}$ computer simulations are shown in Fig. 8a,b for coupon $Z 4$.

The final representative straight line coupon is $\mathrm{Y} 4$ and consists of a full cut across and through the line. These SEM images are shown below in Fig. 9.
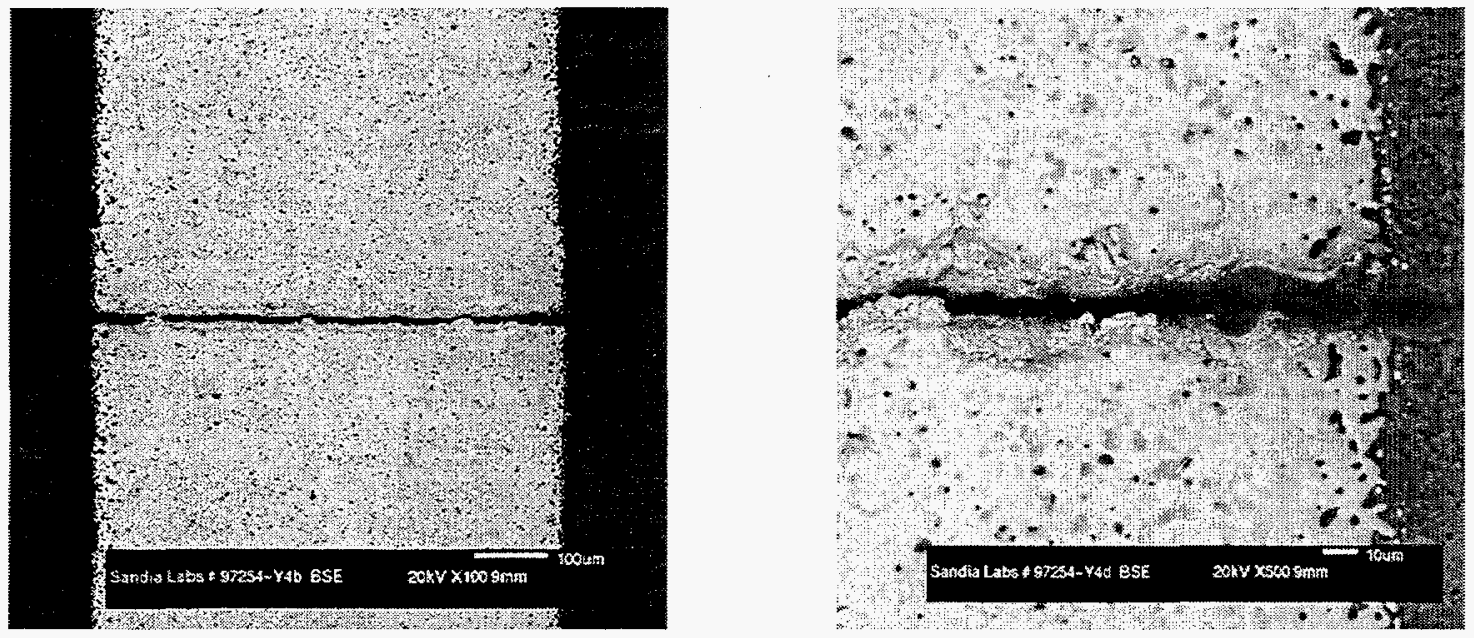

Figure 9. SEM/backscattered emission micrograph of a straight line (coupon Y4) after defects have been induced by laser scribing. 
The corresponding s-parameter reflection and transmission data is shown in Fig. 10a-d for coupon Y4. The data is quite different from coupon $\mathrm{J} 6$ and $\mathrm{Z} 4$ when the line has a complete cut through it. While the transmission data shows the greatest differences after defects at low frequencies, the reflection data shows large differences at all frequencies. The low frequency transmission and reflection computer simulations are shown in Fig. 11 a,b.

The next set of data is for the "t-lines". As previously stated, the depth of the laser cuts was fairly consistent on the straight lines. This was not the case with the $t$-lines. Although several test coupons were supposed to have a $1 / 2$ depth cut, they, in fact, were scribed the entire depth of the transmission line. A portion of the alumina substrate was also affected. Coupon $\mathrm{C} 1$ is representative of this phenomena. Those images are shown in Fig. 12.
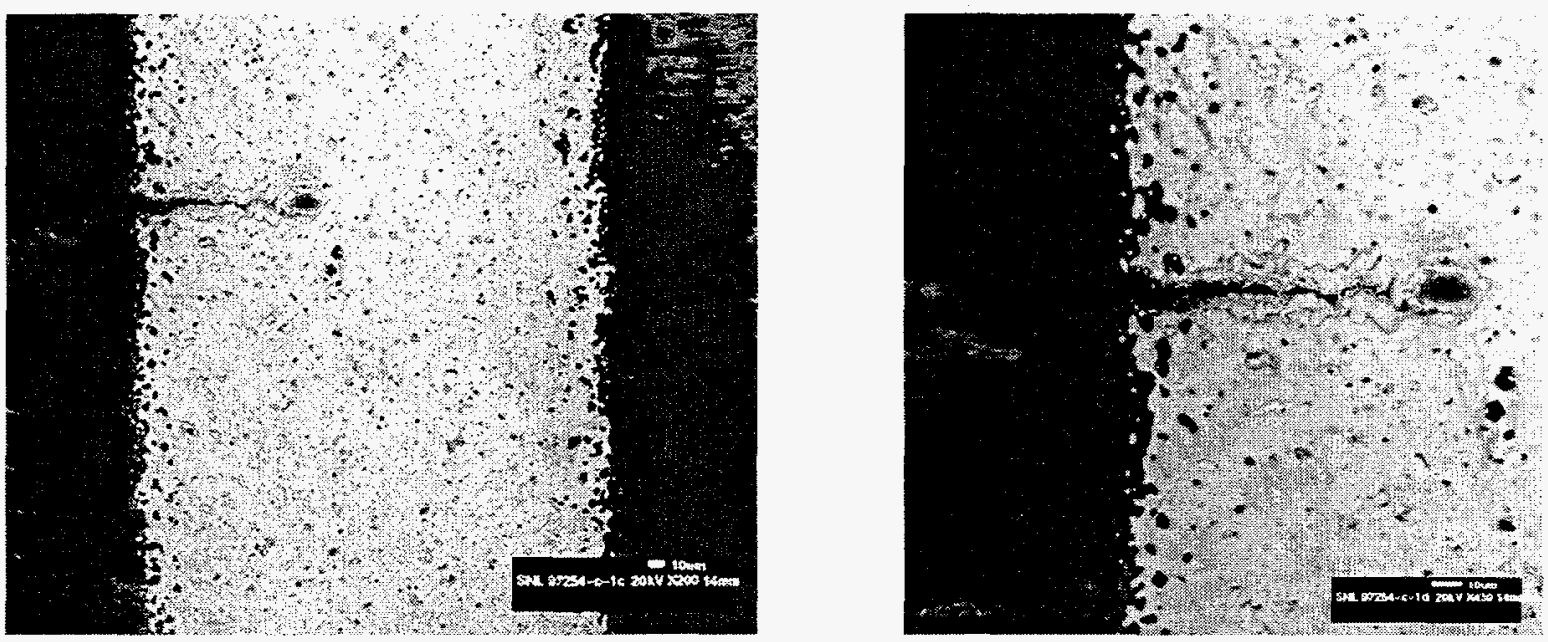

Figure 12. SEM/backscattered emission micrograph of a t-line (coupon C1) after defects have been induced by laser scribing. Note how the alumina substrate is also affected by excessive scribe depth.

Coupons $\mathrm{C} 1$ and $\mathrm{E} 1$ are both supposed to be scribed at $1 / 2$ depth. The s-parameter reflection and transmission data is shown in Fig. 13a-d for coupon $\mathrm{Cl}$ while Fig. 14a-d illustrates coupon E1. Note how both sets of reflection and transmission data are very similar even though $\mathrm{Cl}$ is $1 / 3$ cut and $\mathrm{E} 1$ is $1 / 2$ cut across the line. There are, however, slight differences after laser scribing in the reflection data at higher frequencies. Both are scribed completely through the depth of the line, however. The depth of the cut appears to have a greater influence on the s-parameter measurements than the cut across the width of the line does in this case since the laser scribing is through the entire depth of the line.

Coupon $\mathrm{S} 1$ is also a t-line scribed completely across and through the line. Those SEM images are shown in Fig. 15. 

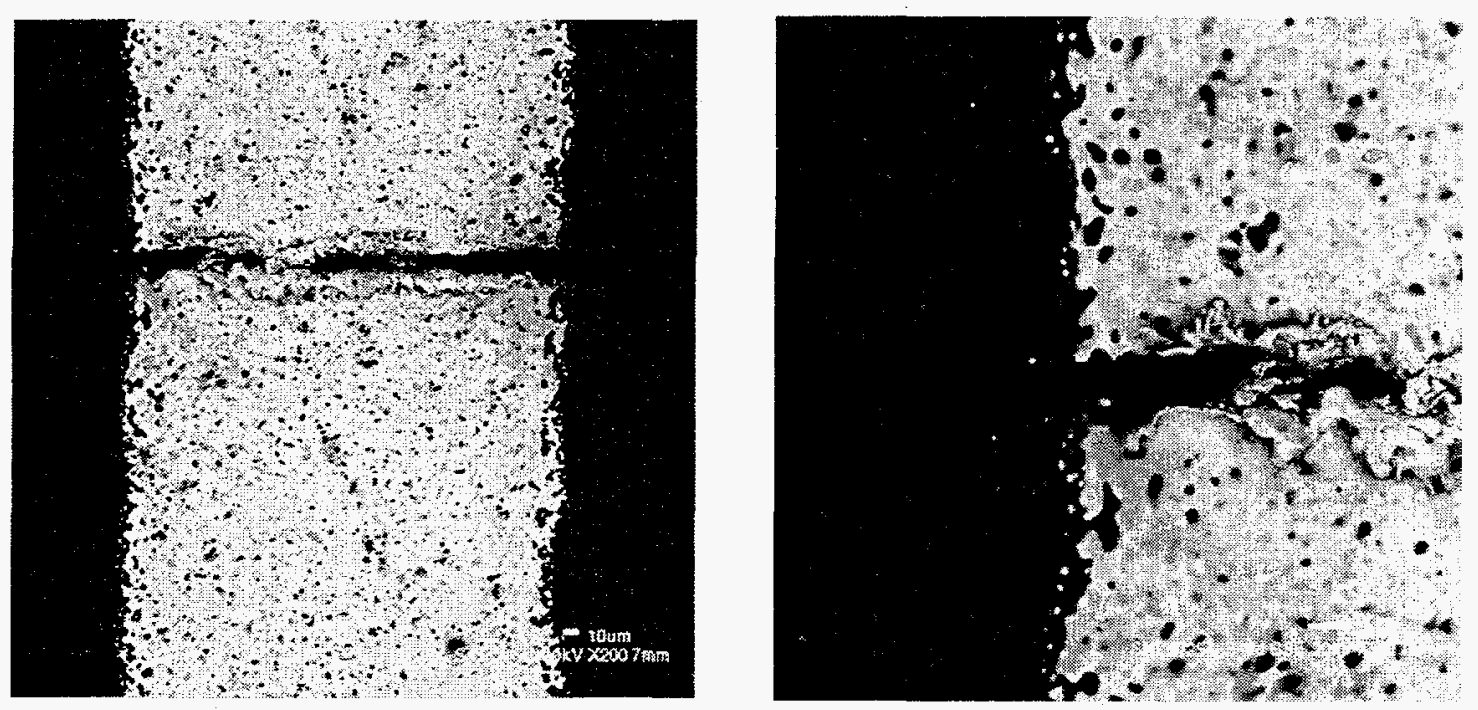

Fig. 15. SEM/backscattered emission micrograph of a t-line (coupon S1) after defects have been induced by laser scribing. The alumina substrate is also affected by excessive scribe depth.

The s-parameter reflection and transmission data is shown in Fig. 16 for coupon S1. The differences are quite significant on this coupon after laser scribing. The reflection data shows large differences in the signals when defects are present at all frequencies but most noticeably at $10 \mathrm{GHz}$. The greatest differences in the transmission data after defects are induced are at frequencies below $30 \mathrm{GHz}$ with the most pronounced differences seen at approximately 5 $\mathrm{GHz}$ and diminishing somewhat as they approach $50 \mathrm{GHz}$.

\section{CONCLUSIONS}

The high frequency simulation of microstrip transmission line with a model of artificially induced microcracks was completed. The implementation of high frequency characterization can be used to detect and measure defect growth in a transmission line. The modeled and measured results show that as the crack increases in size, there is a significant increase in insertion loss and return loss on the line. There is also a direct relationship in resonant frequency shifts as the crack size increases.

\section{REFERENCES}

1. M. Polcyzski, M. Seitz, R. Hirthe, T. Hoeller, "Use of AC Electrical Impedance Techniques for Monitoring Microstructural Changes in Electronic Materials", Proceedings of the 1991 International Symposium on Microelectronics, Orlando, FL., pp. 431-435, 1991. 


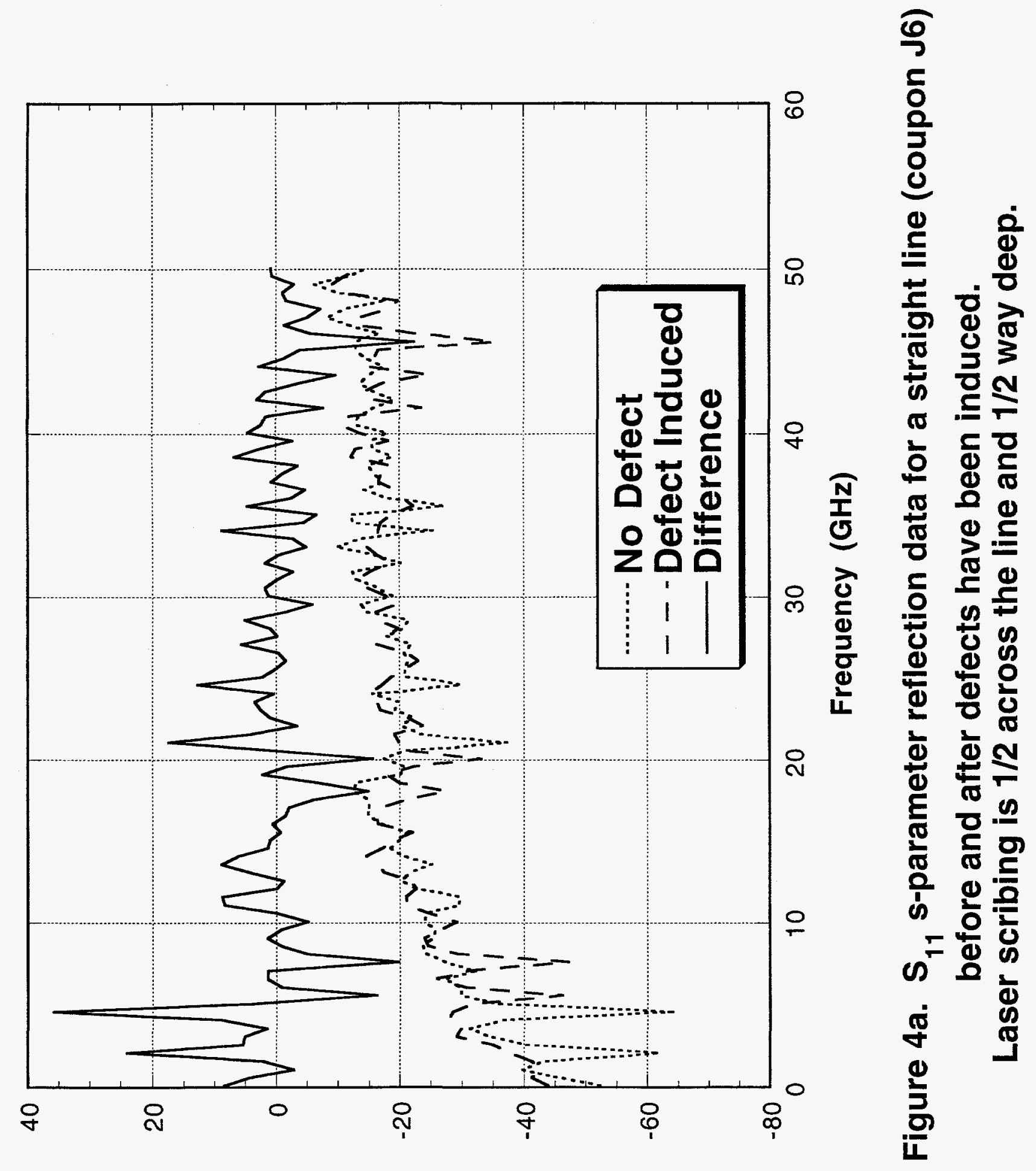

(gp) әрnџ!uбew 


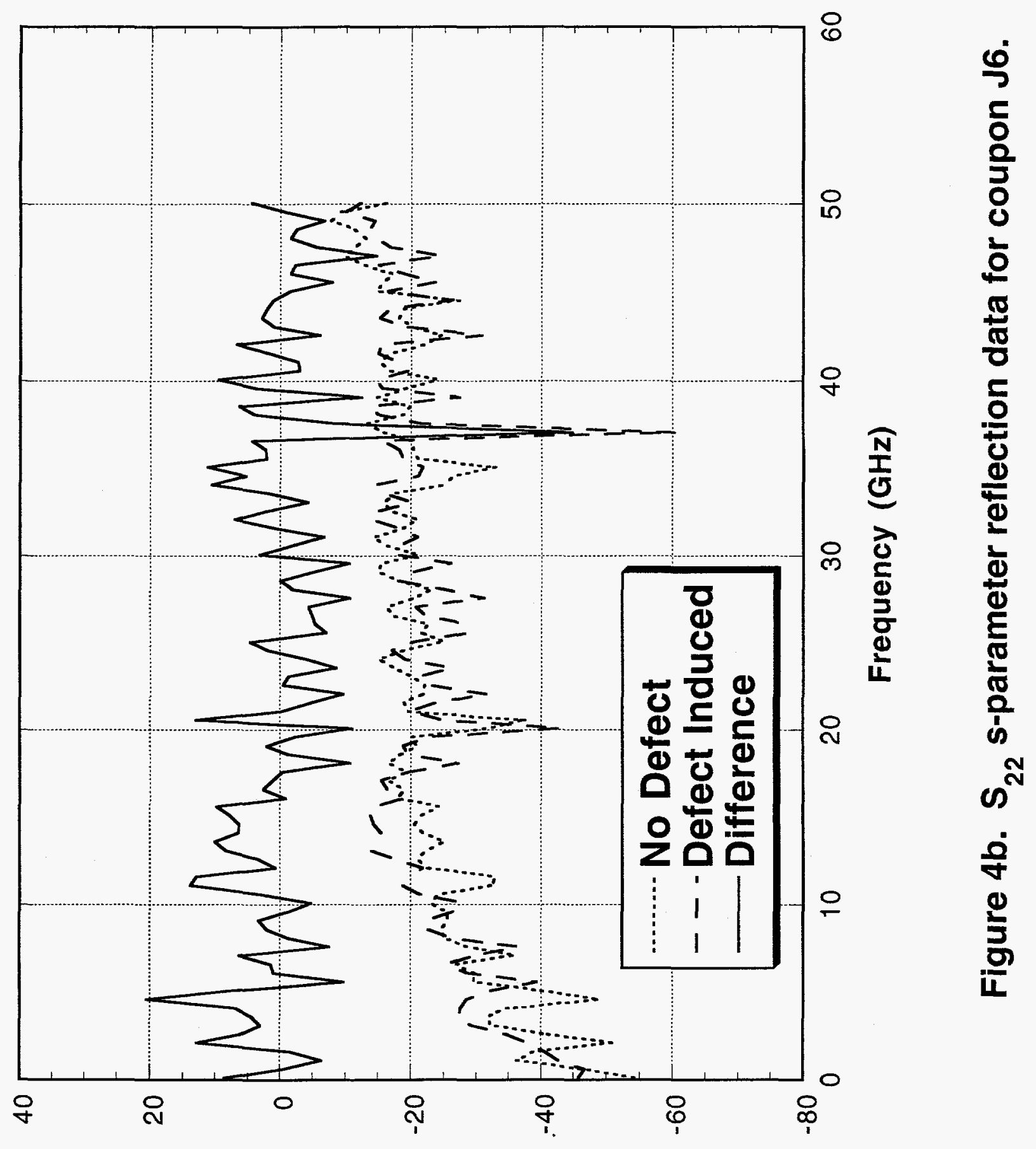

(gp) әpnџ!u6ew 


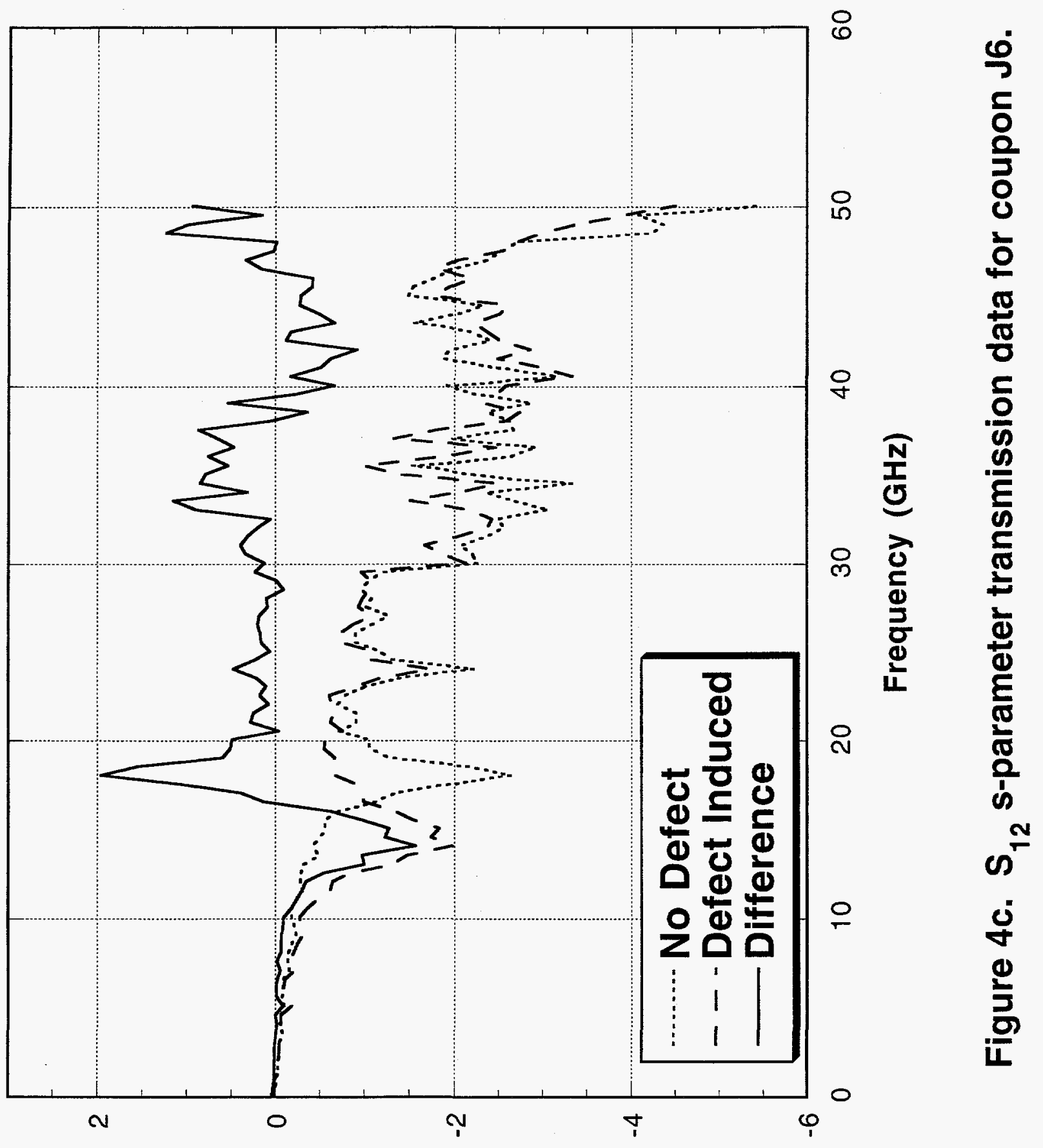

(gp) әpn!!u6ew 


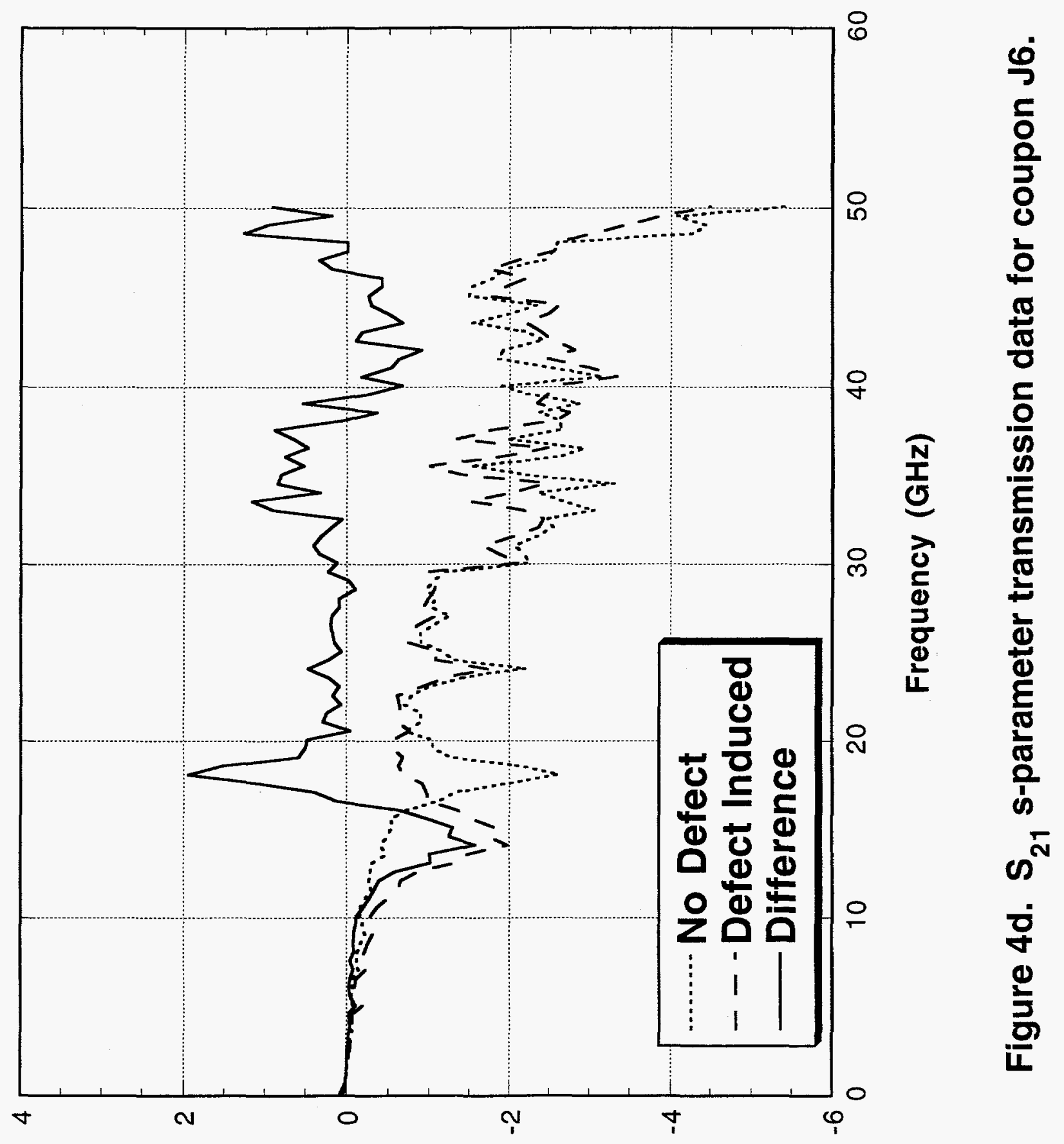

(gp) әрnџ!uбew 


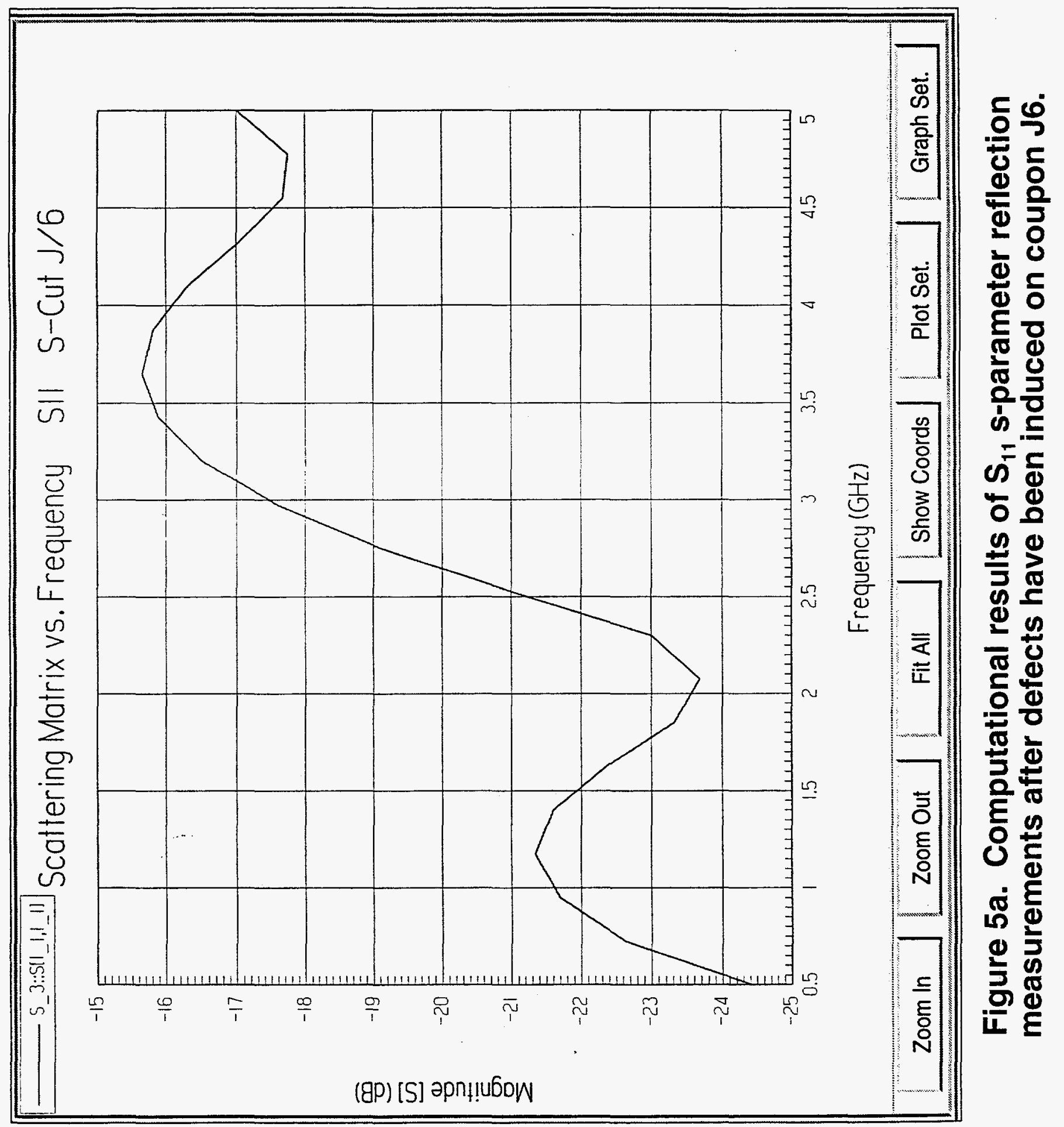




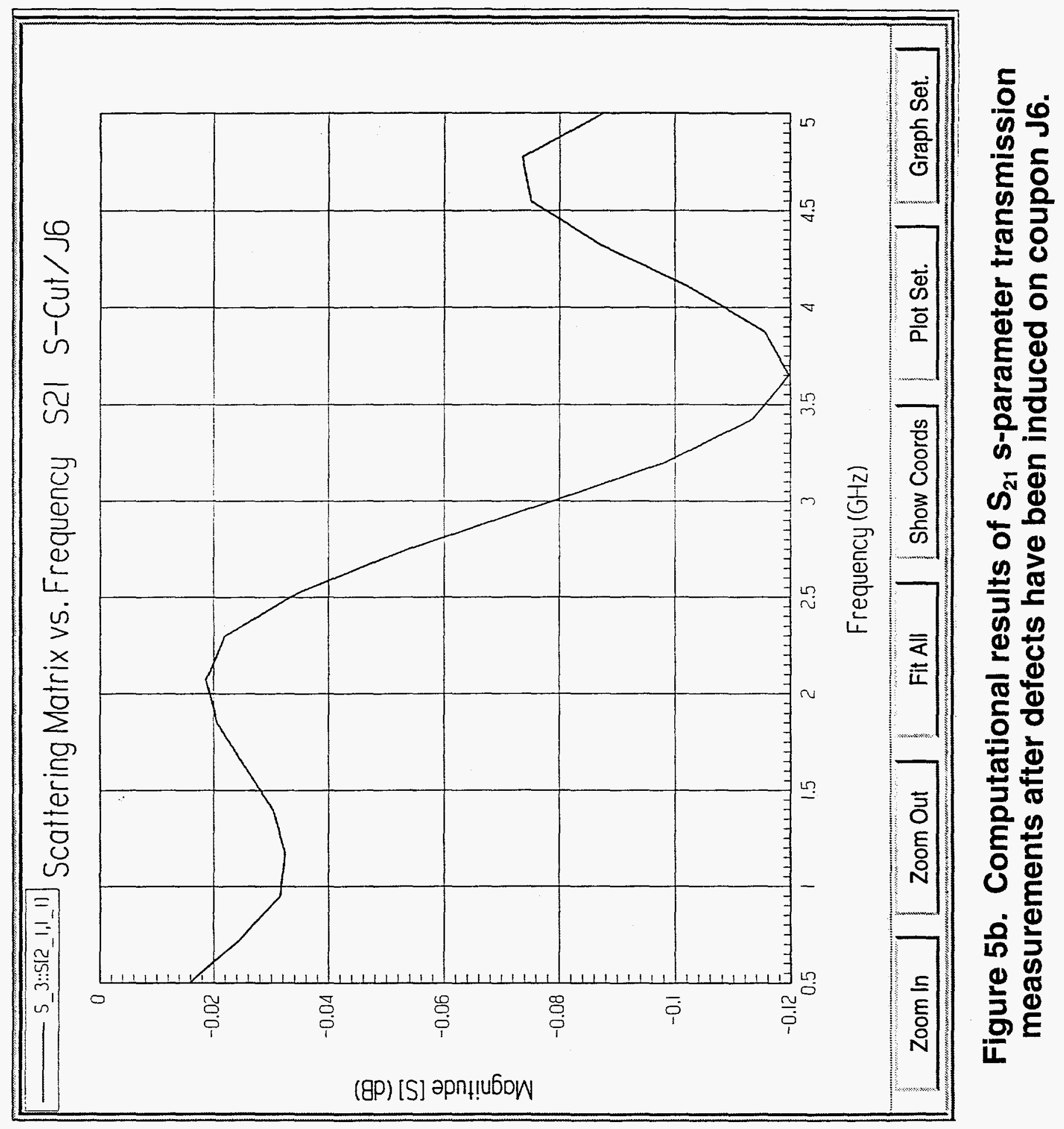




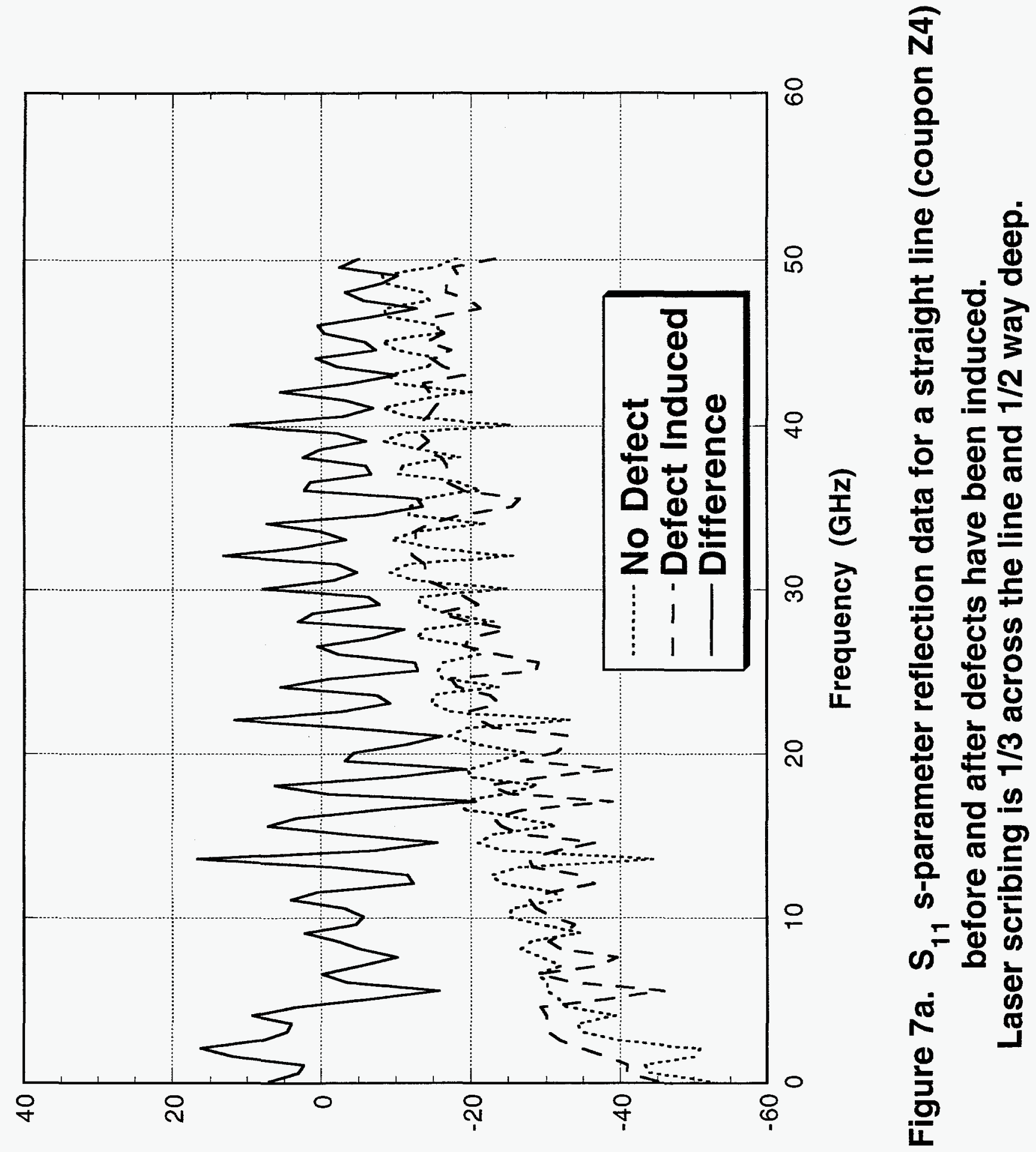

(ap) әpnџ!u6ew 


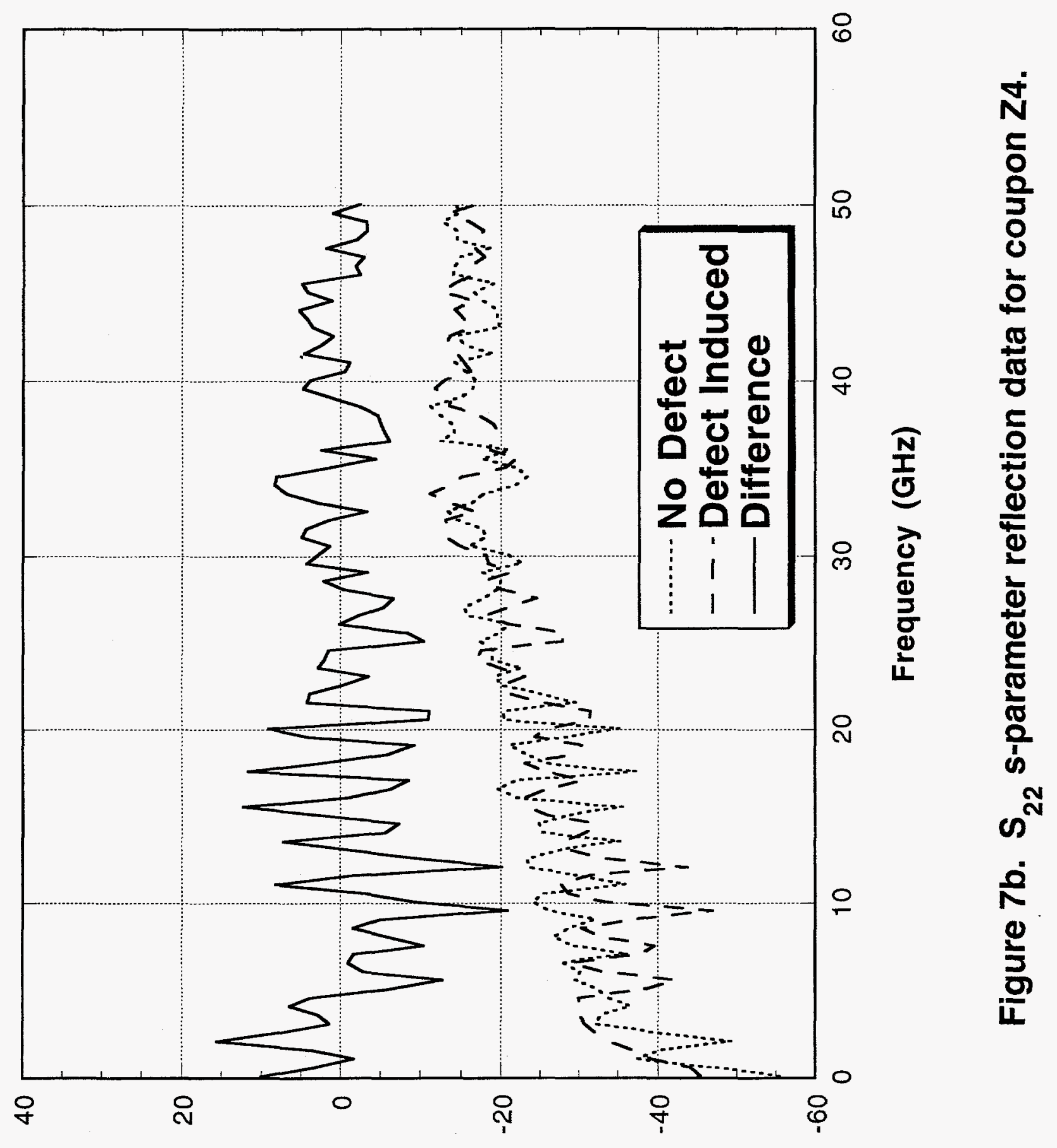

(ap) әpnч!u6ew 


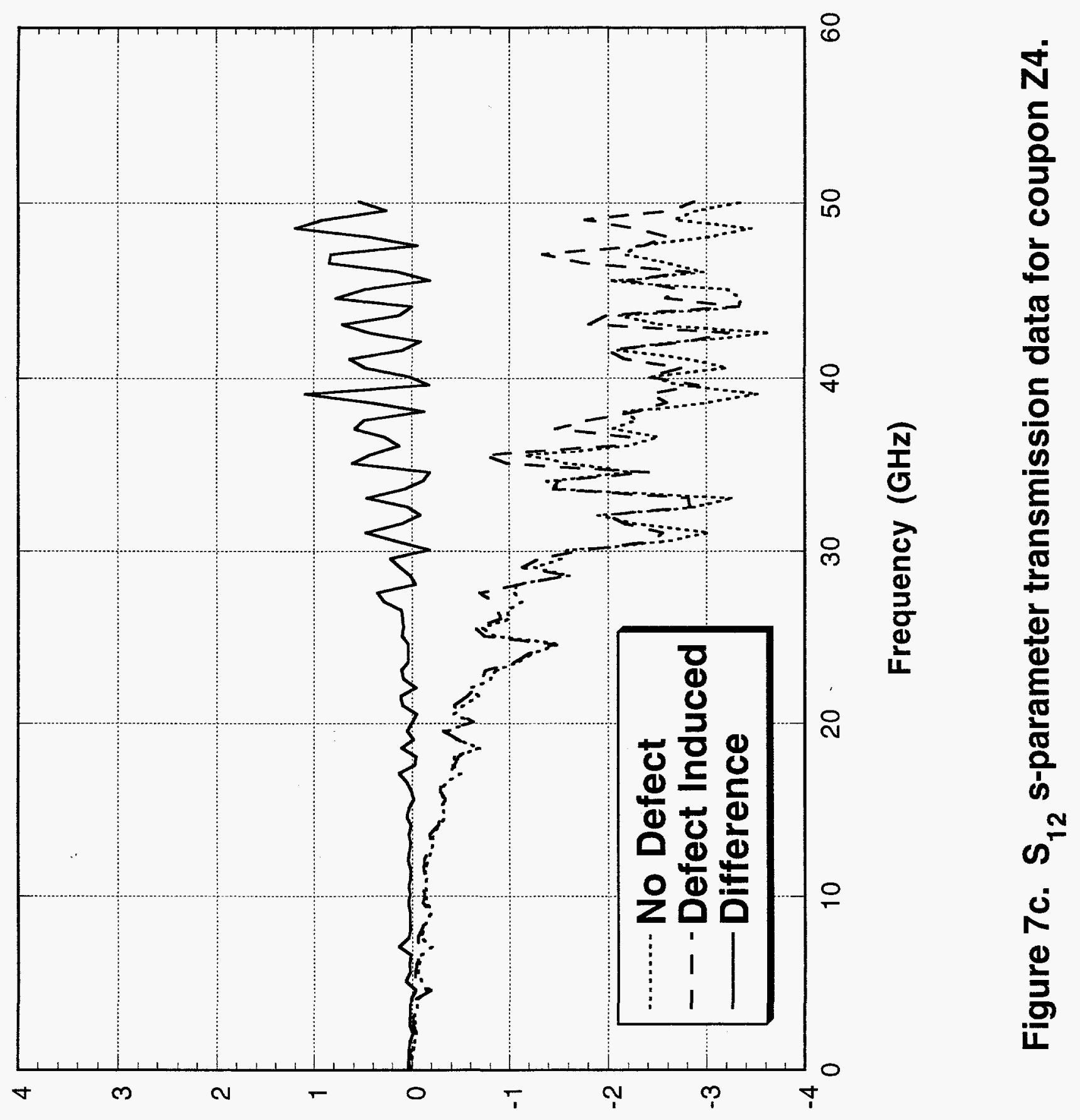

(ap) әpnџ!uбew 


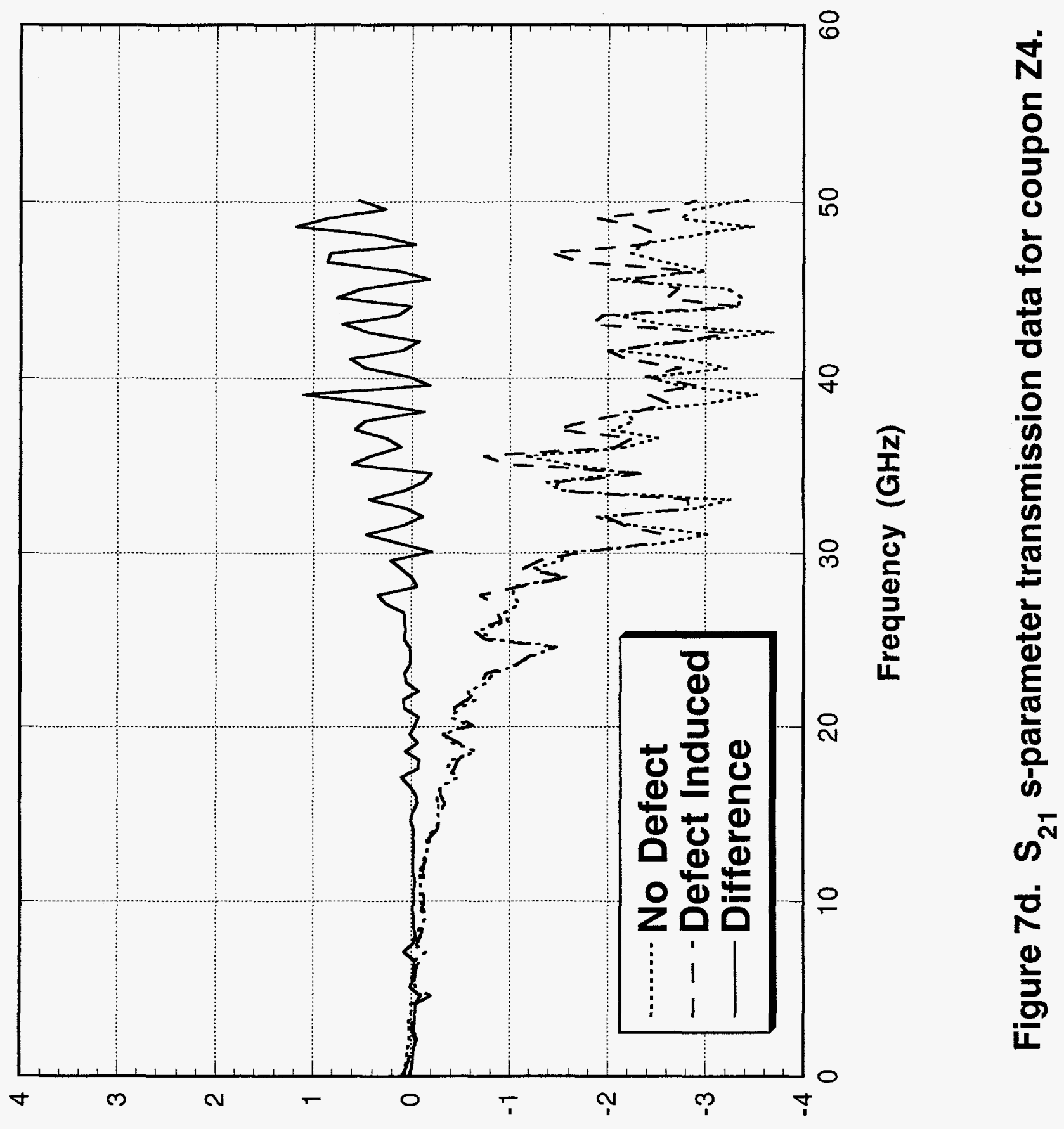

(gp) әрnџ!u6ew 


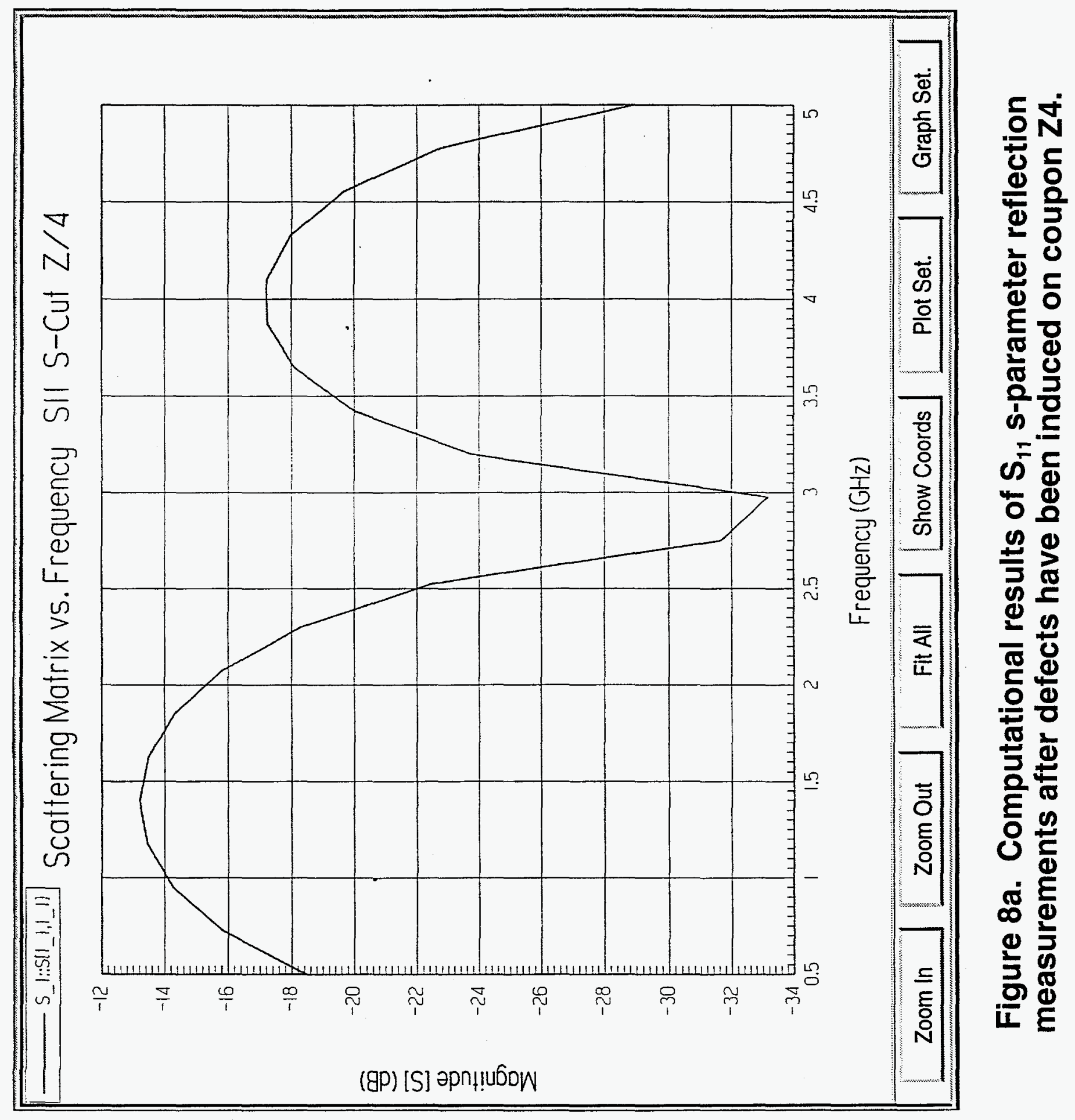




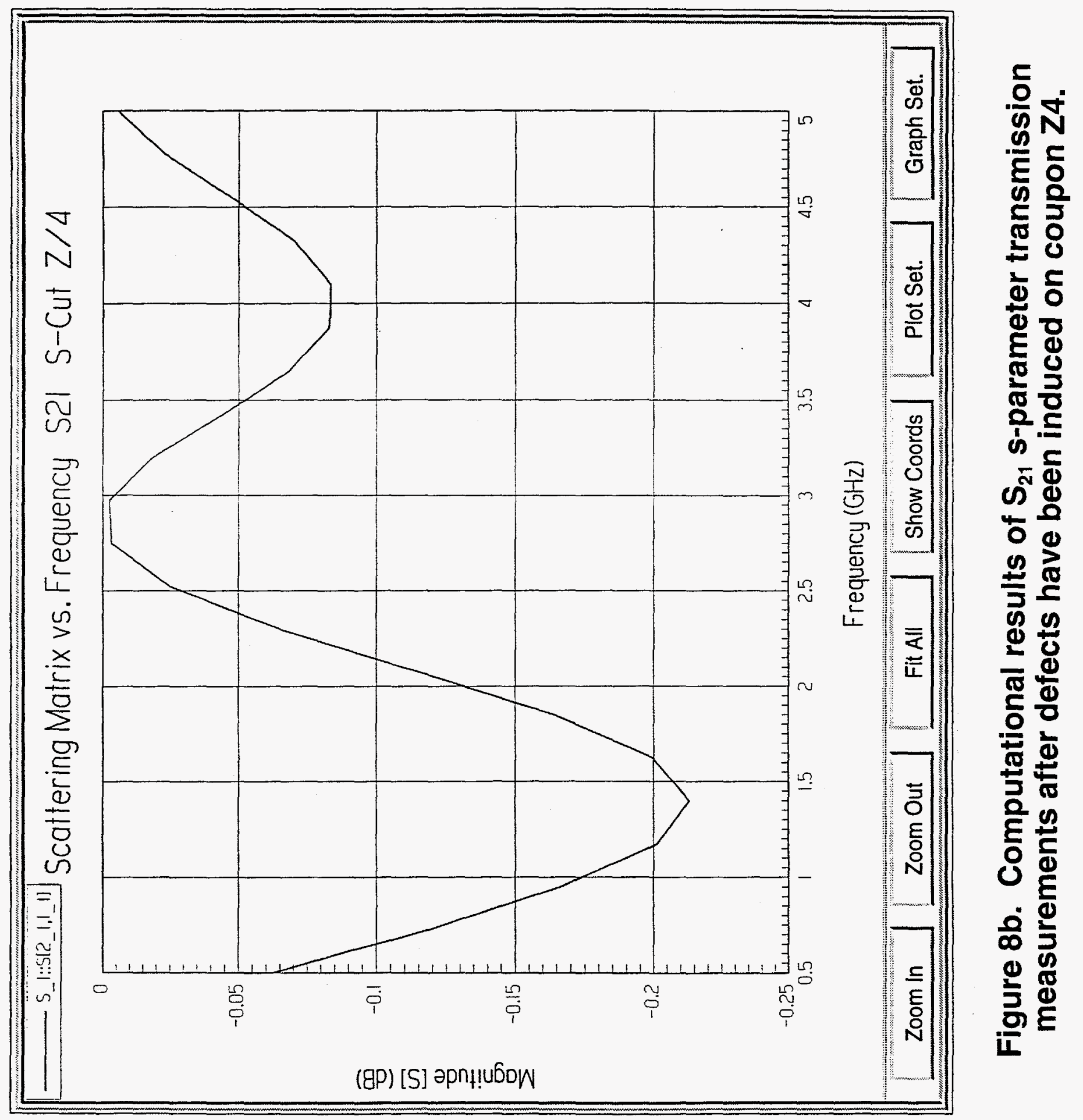



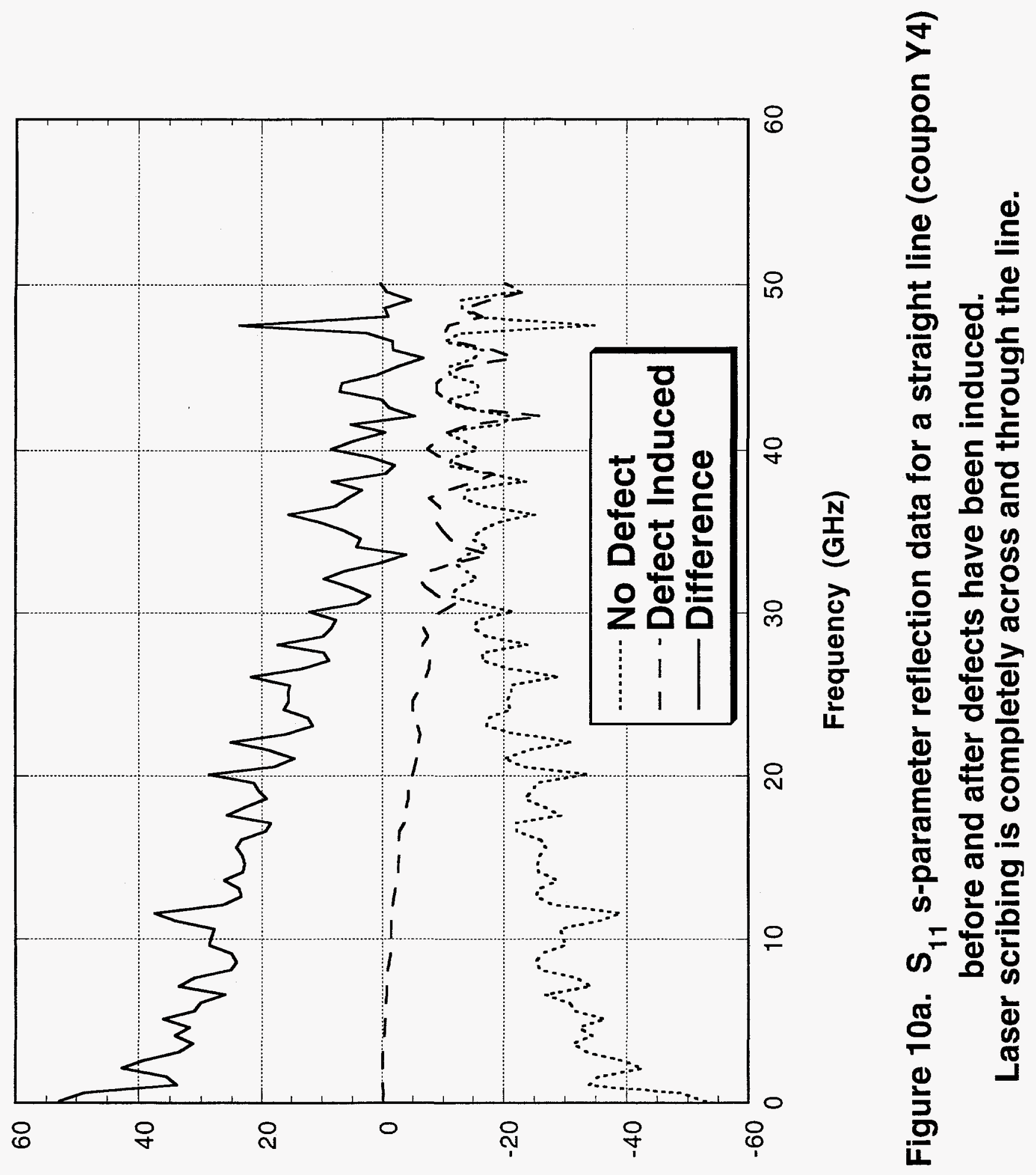

(gp) әpnџ!u6ew 


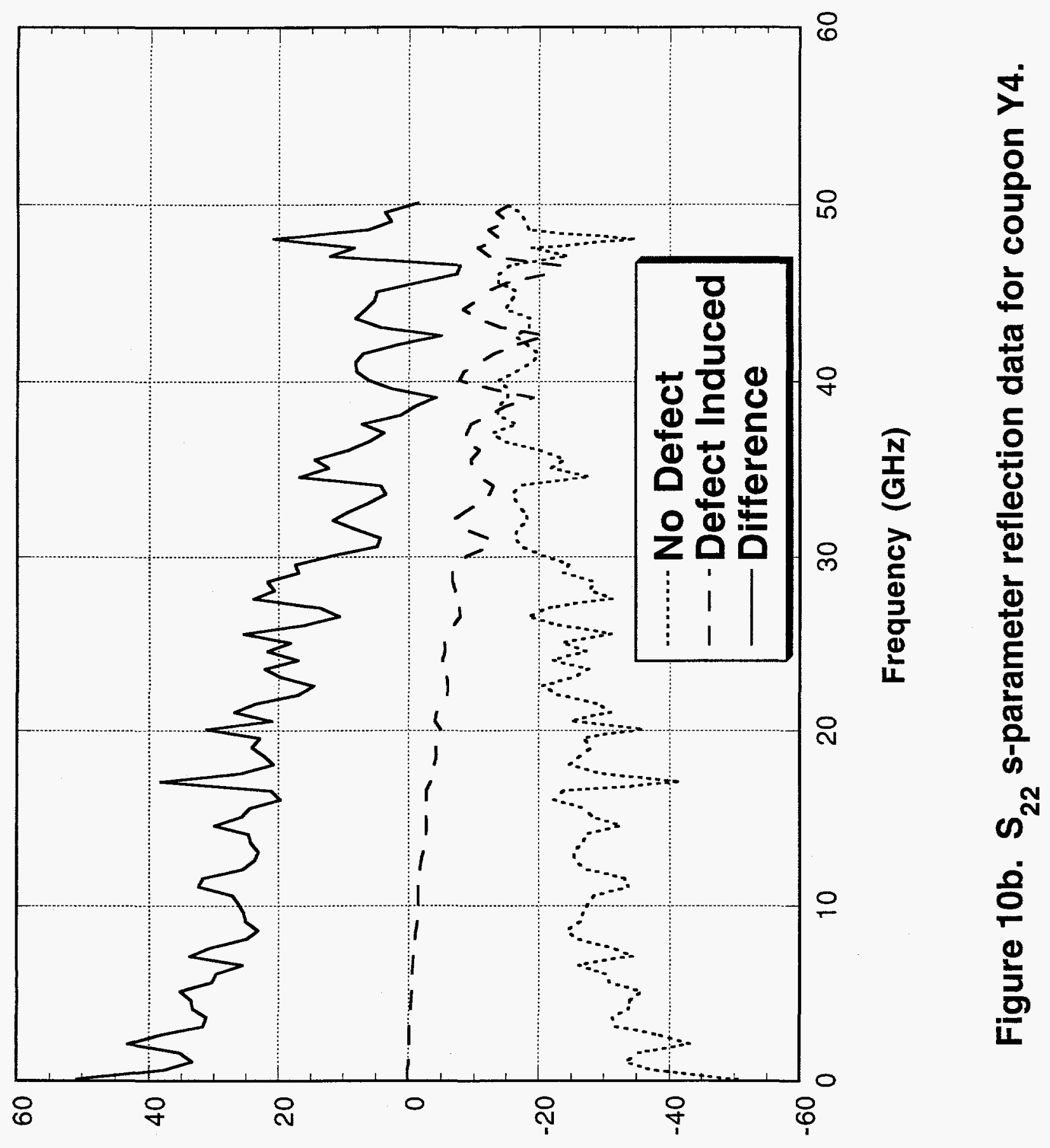

(gp) әpnџ!u6ew 


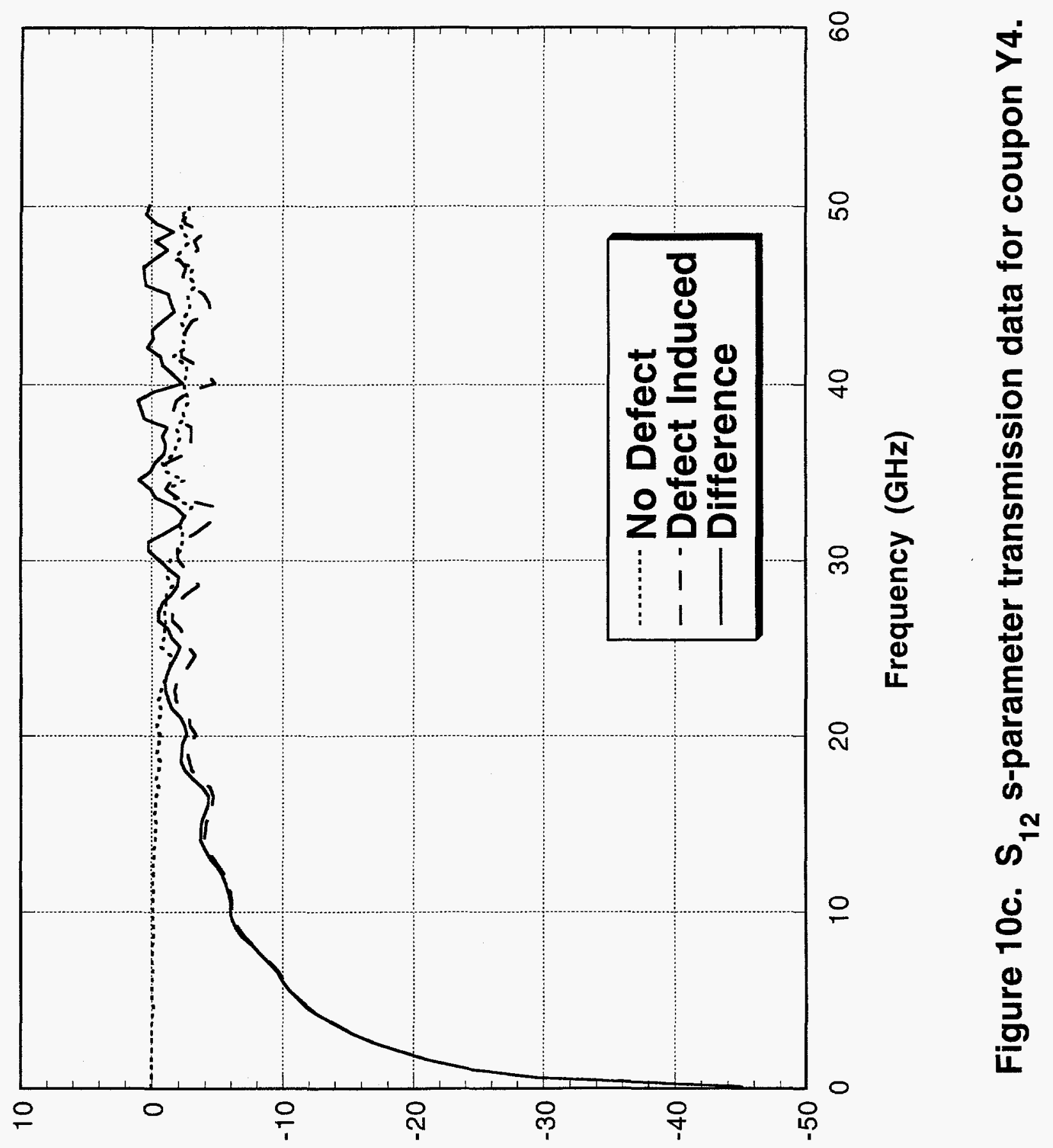

(gp) әрnџ!u6ew 


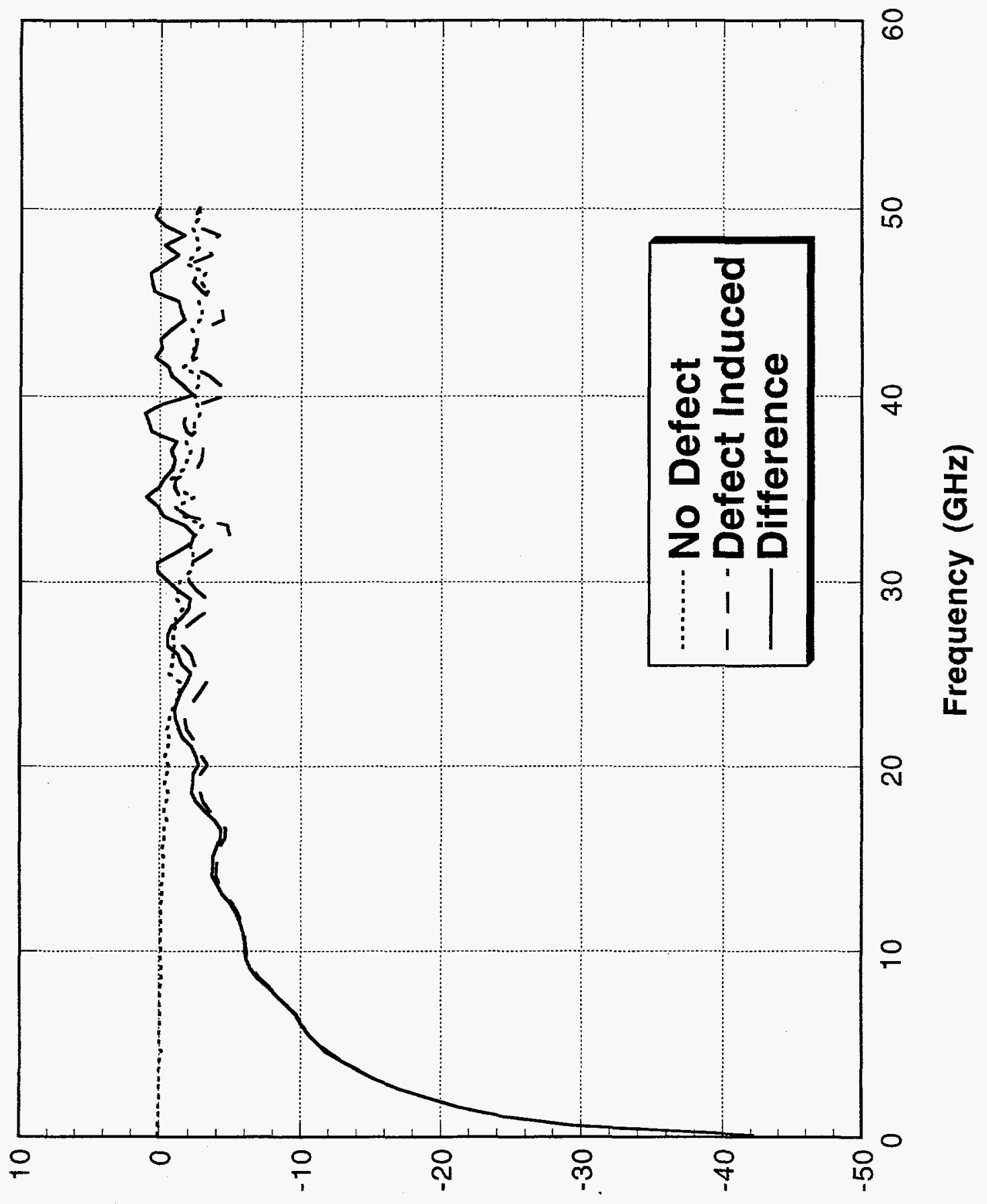

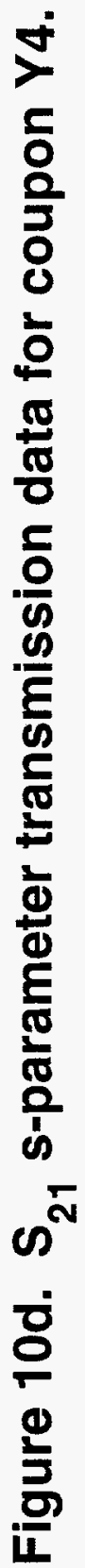

(gp) әpnџ!u6ew 


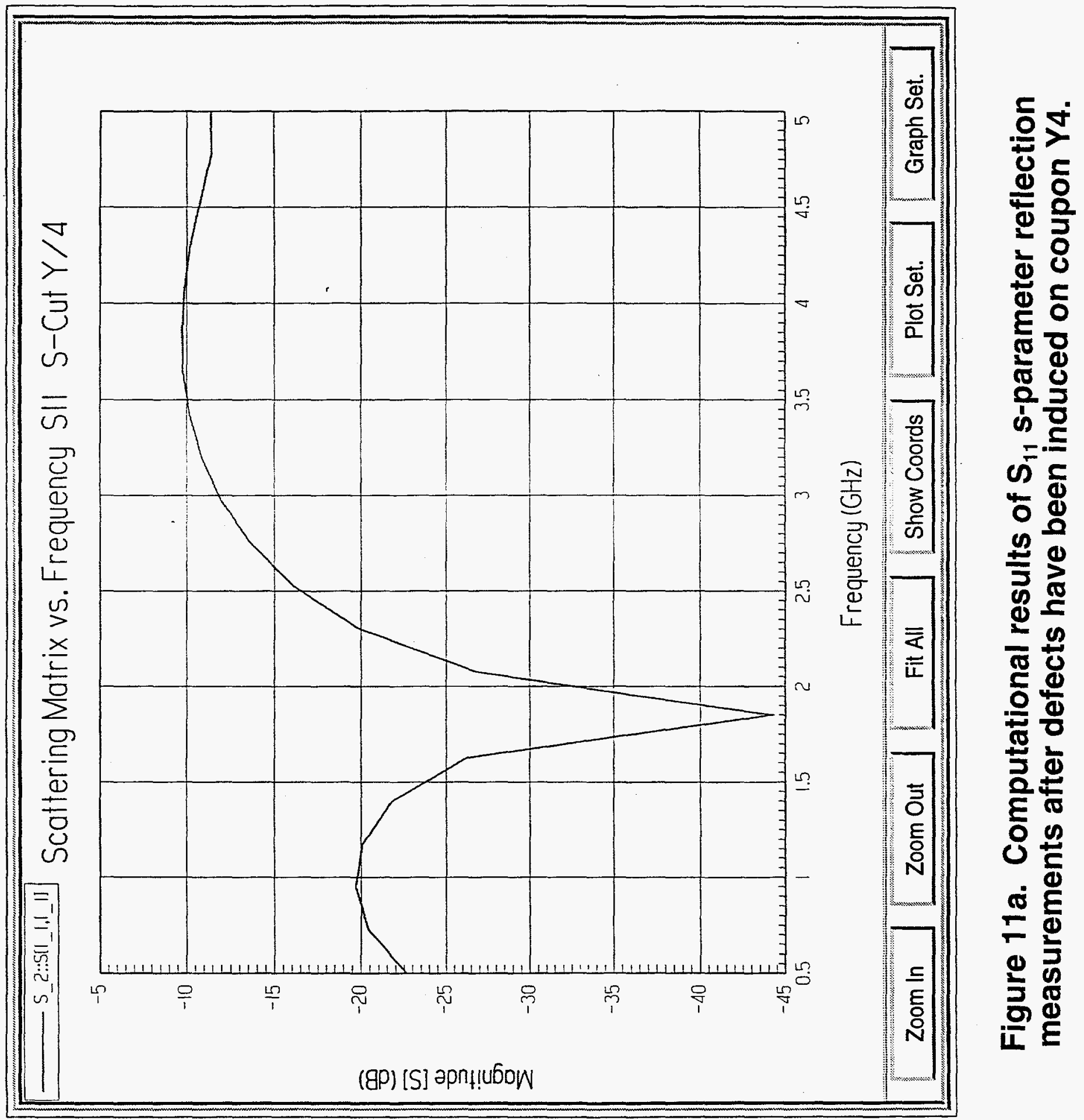



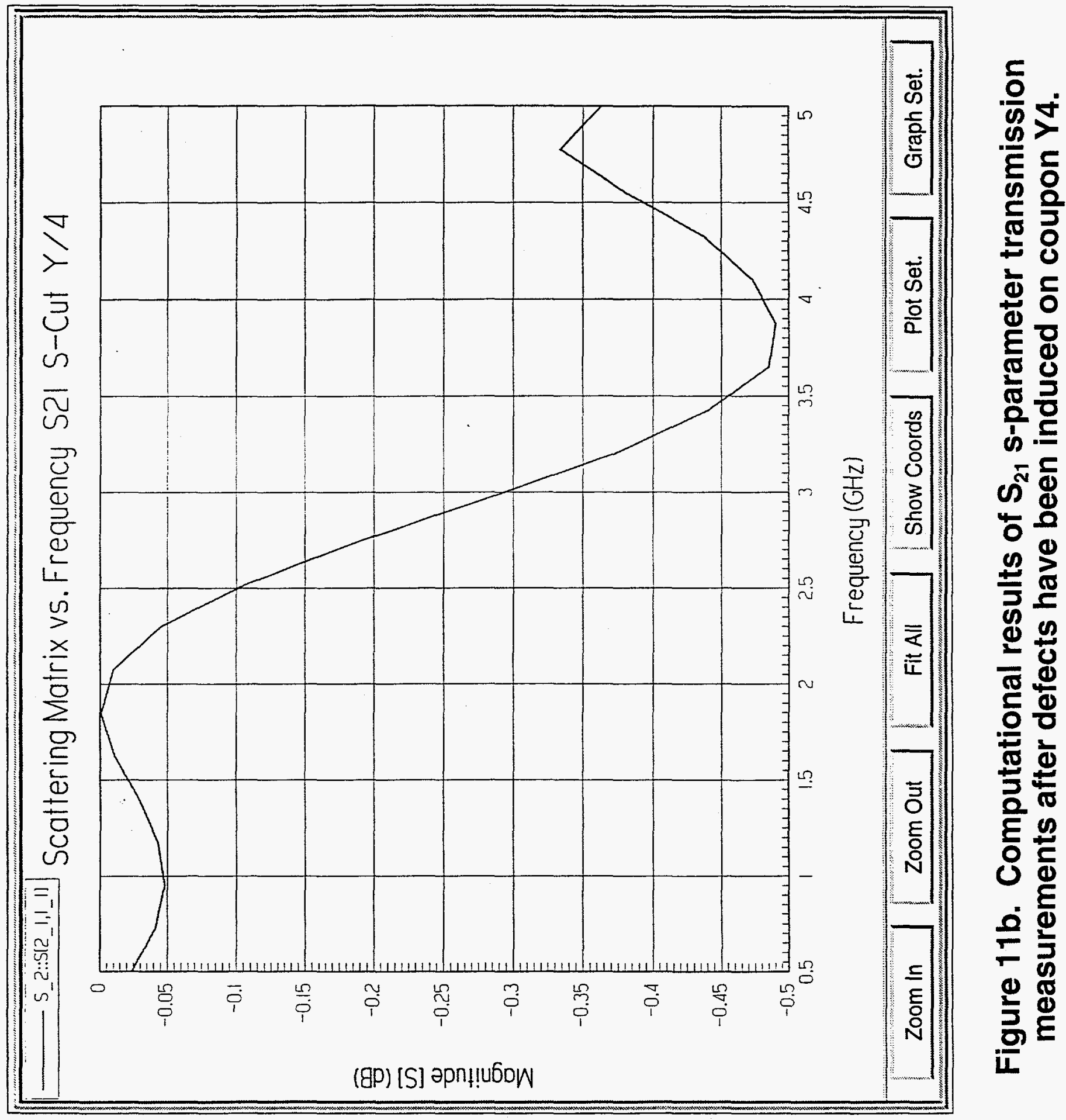


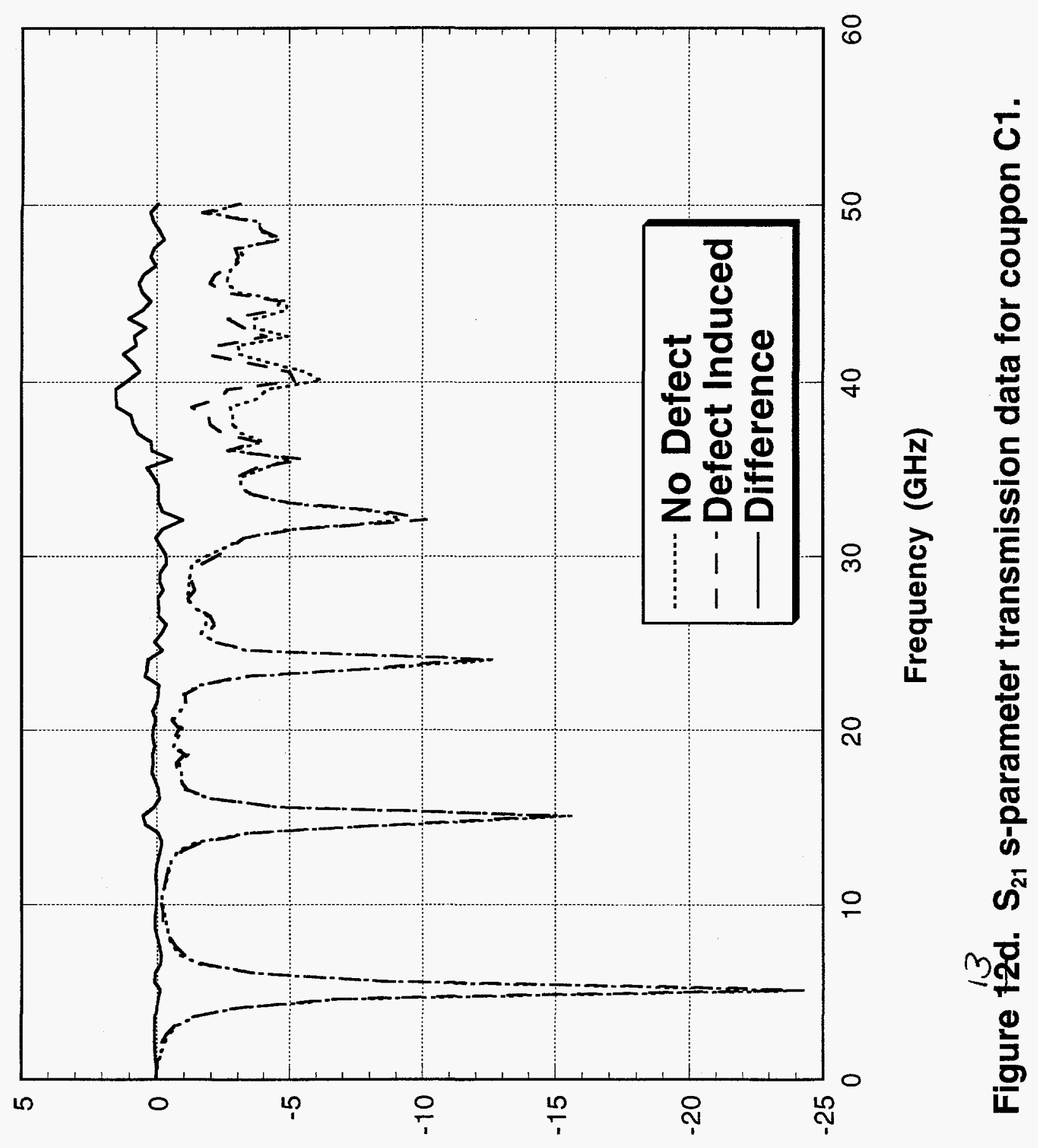

(gp) әpnџ!u6ew 


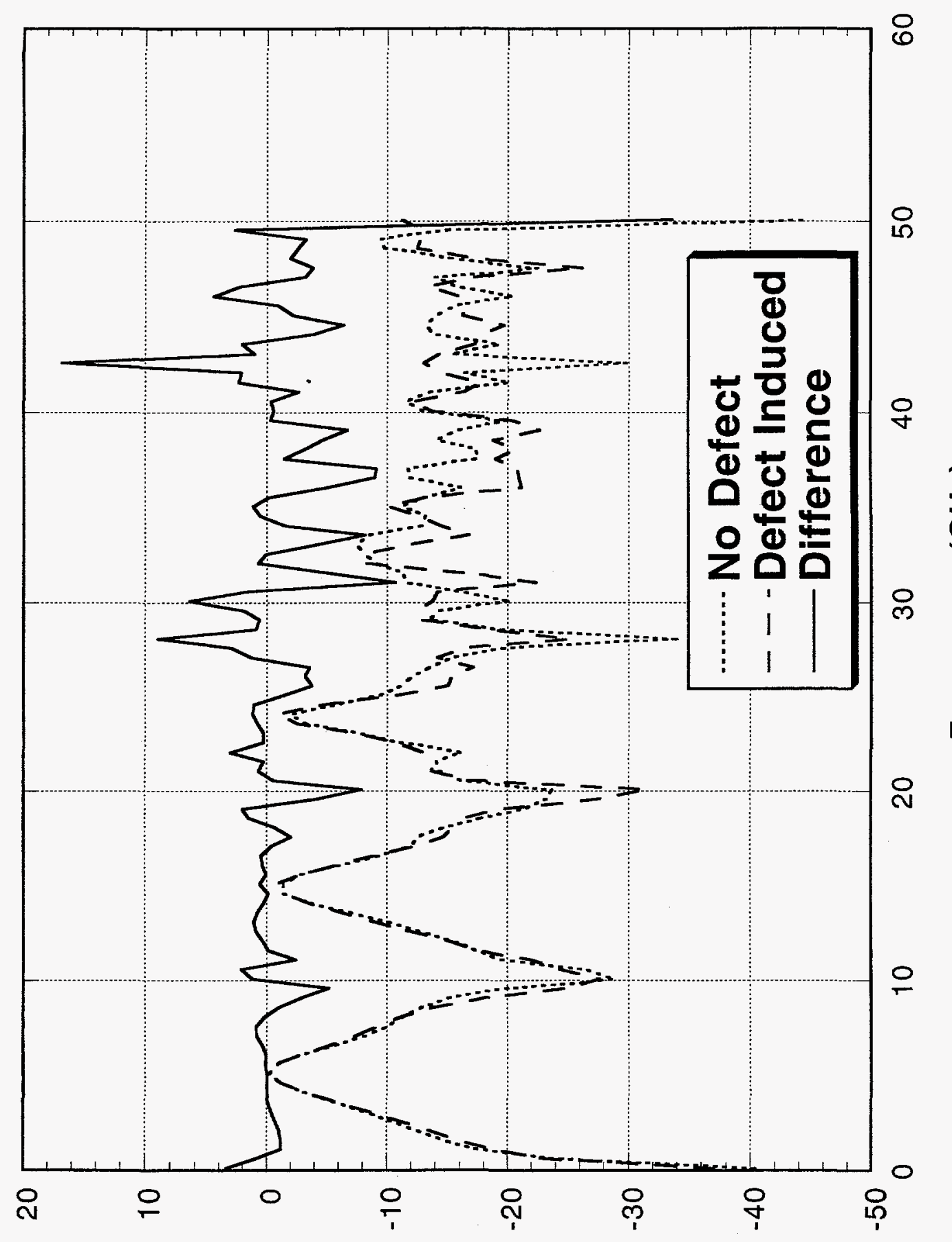

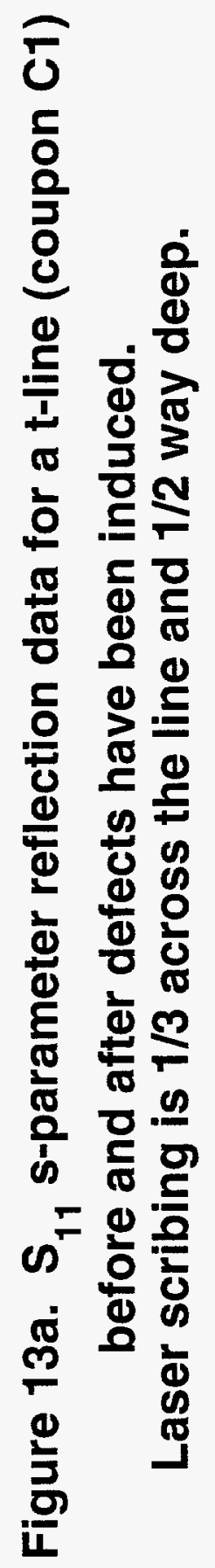

(gp) әpn!!uбew 


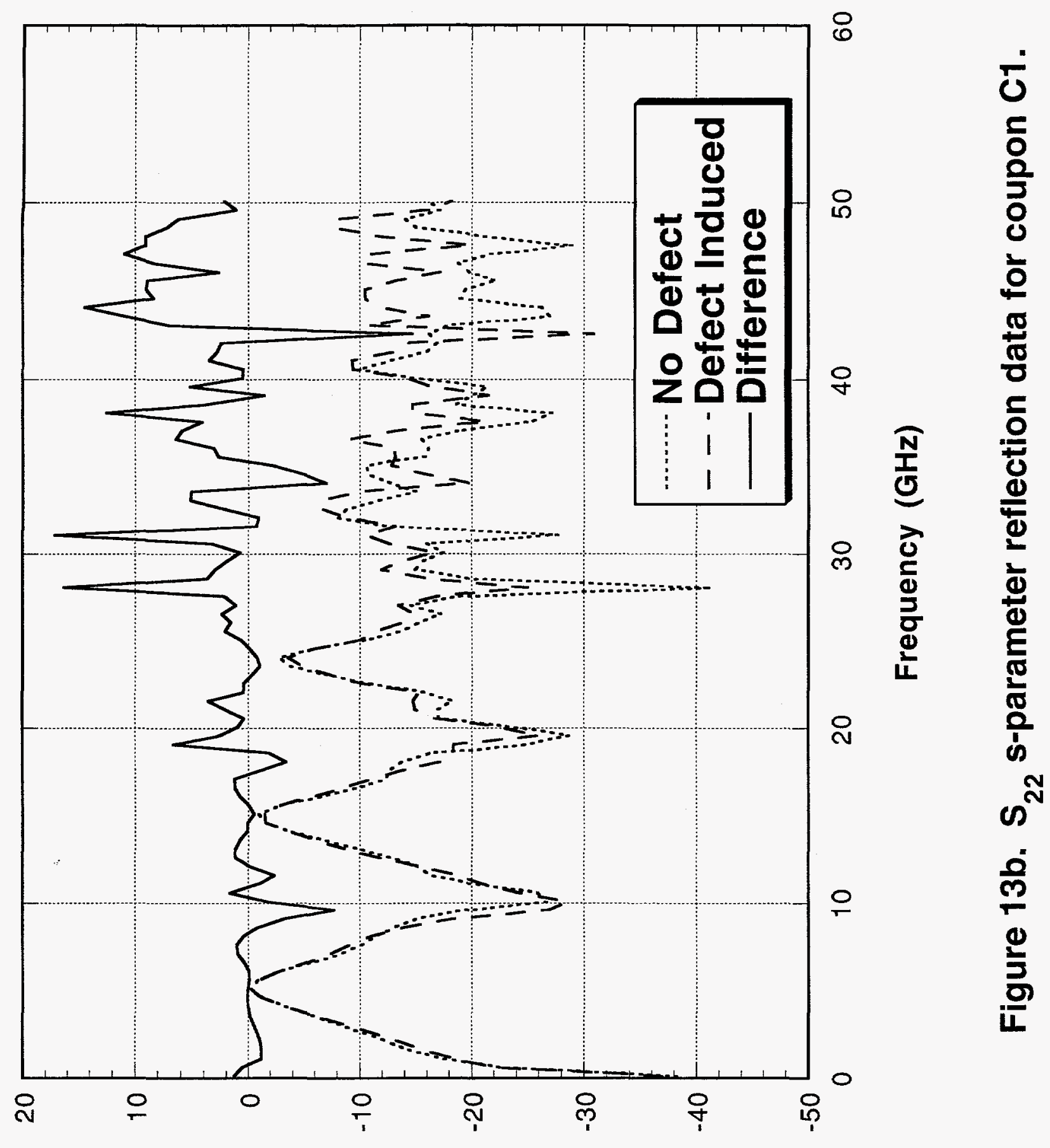

(ap) әрnұ!uбew 


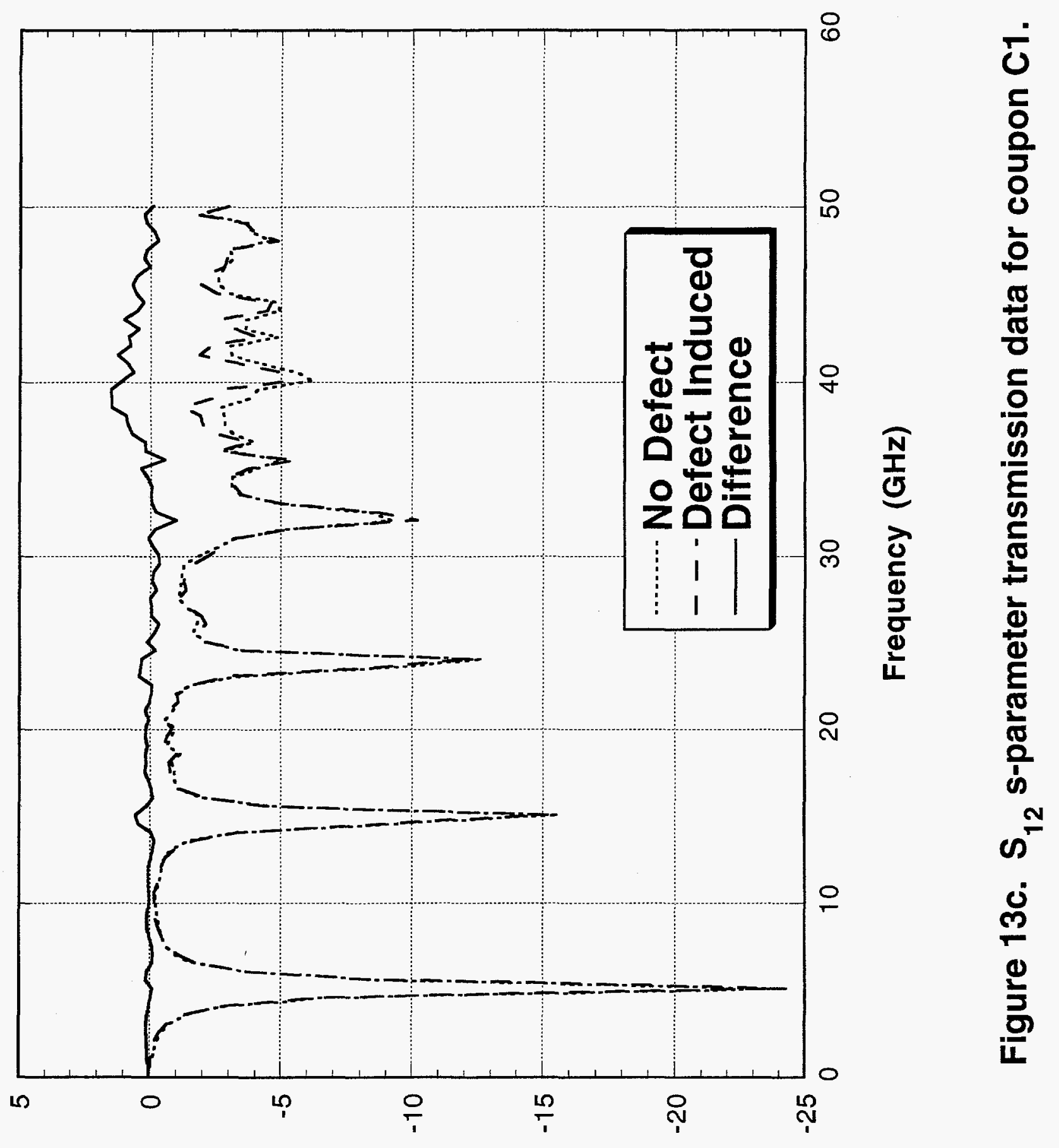

(ap) әpnұ!u6ew 


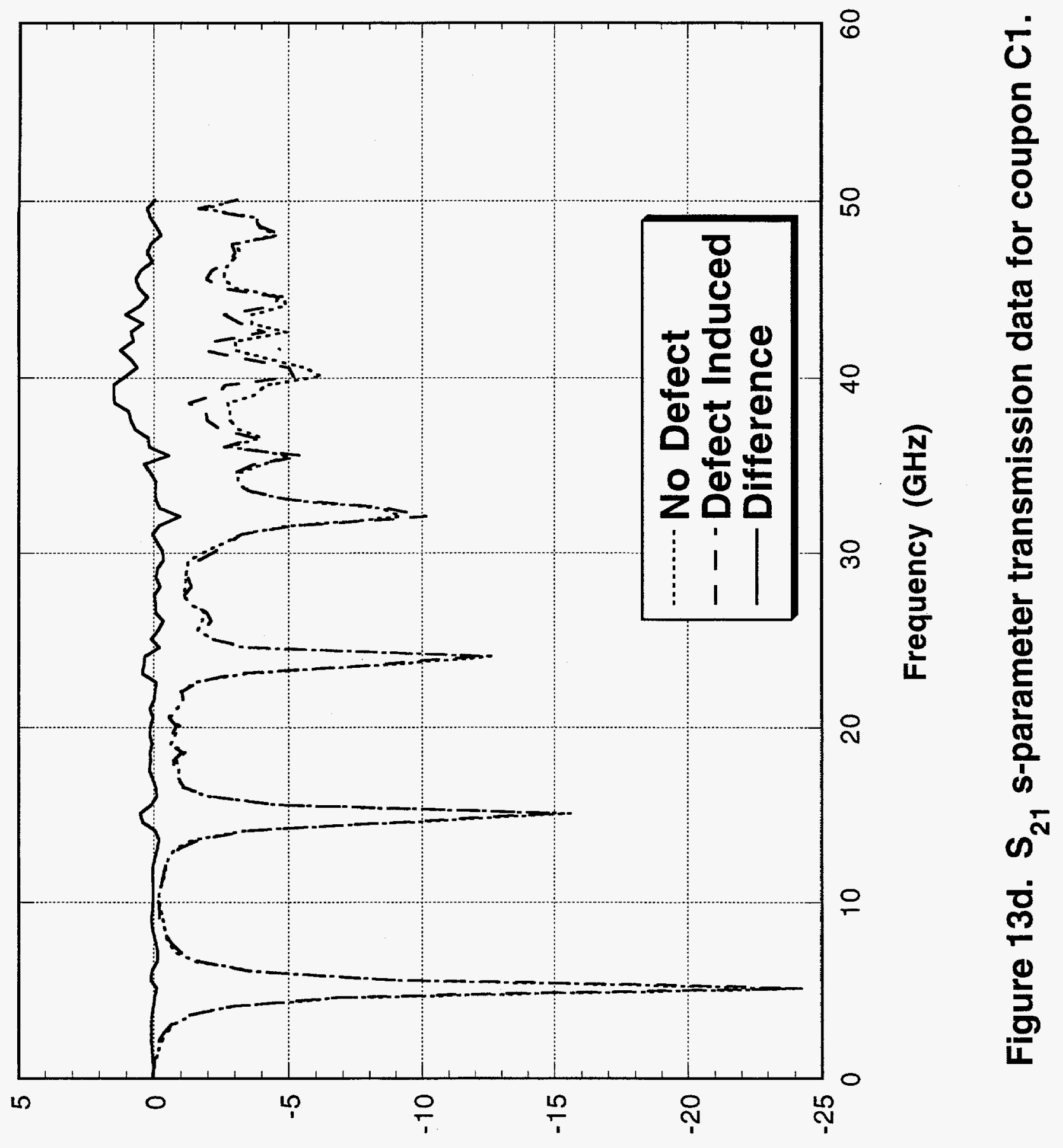

(ap) әрnџ!u6ew 

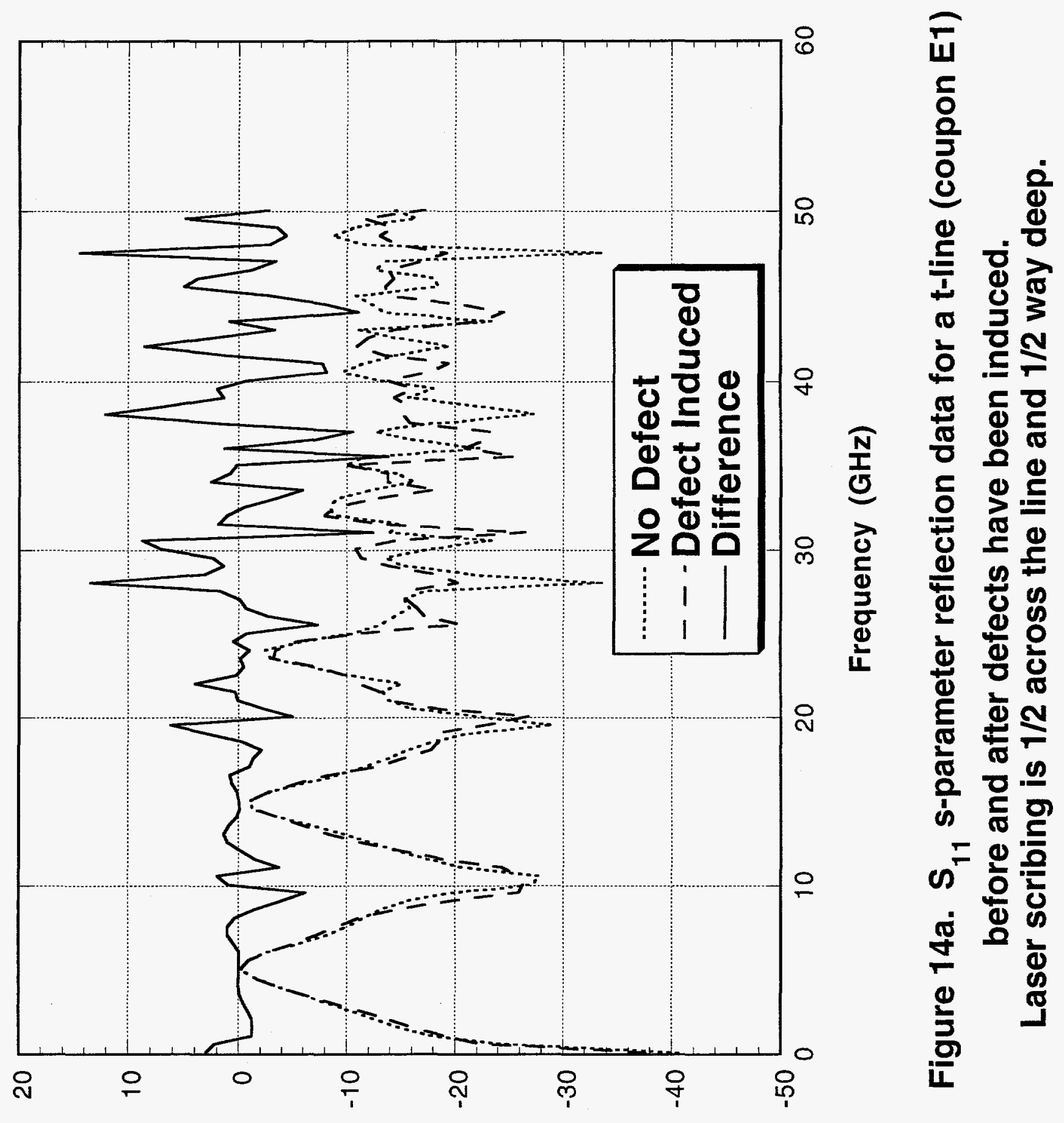

(gp) әрnч!̣6ew 


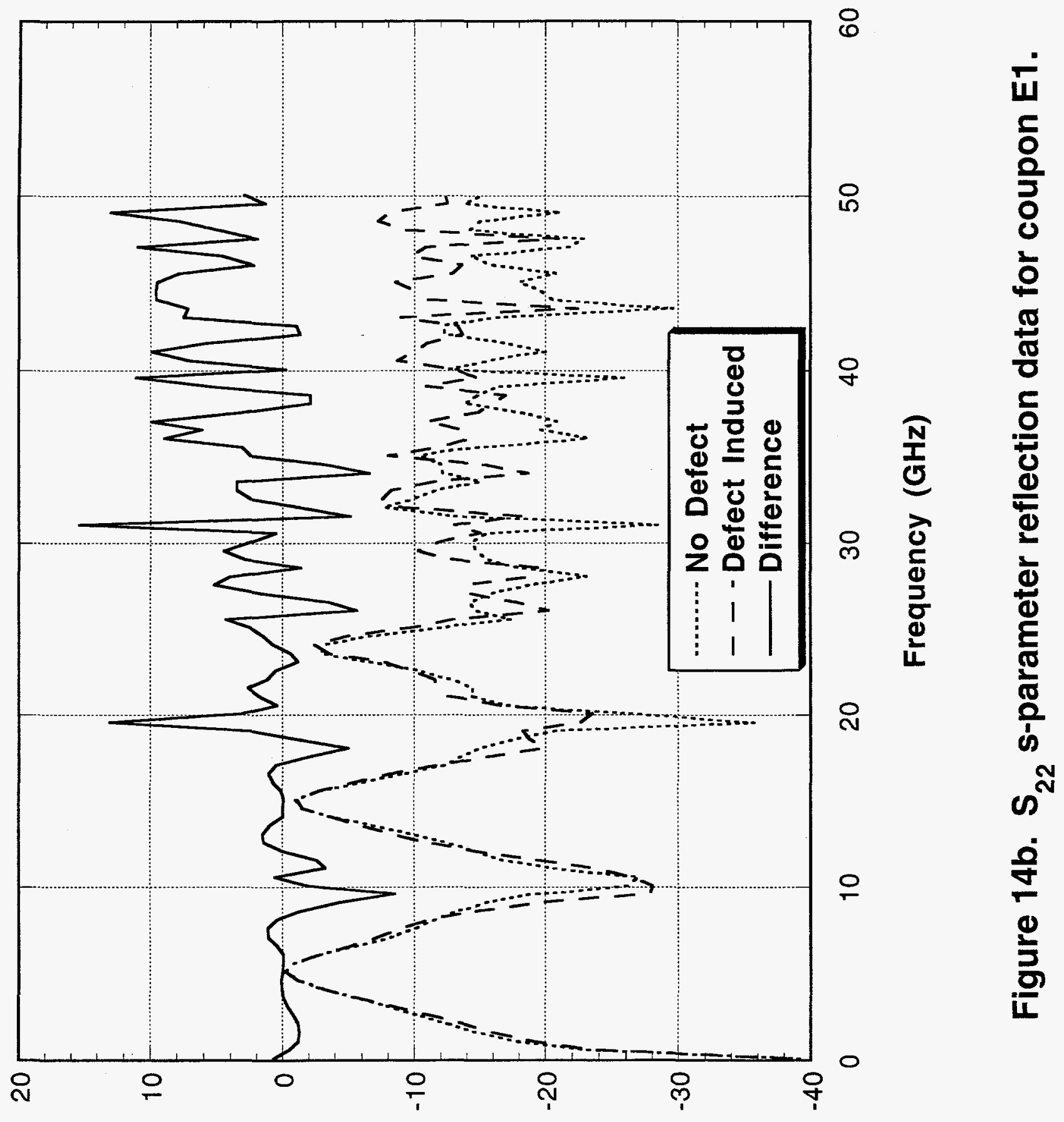

(gp) әрnұ!ฺ6еw 


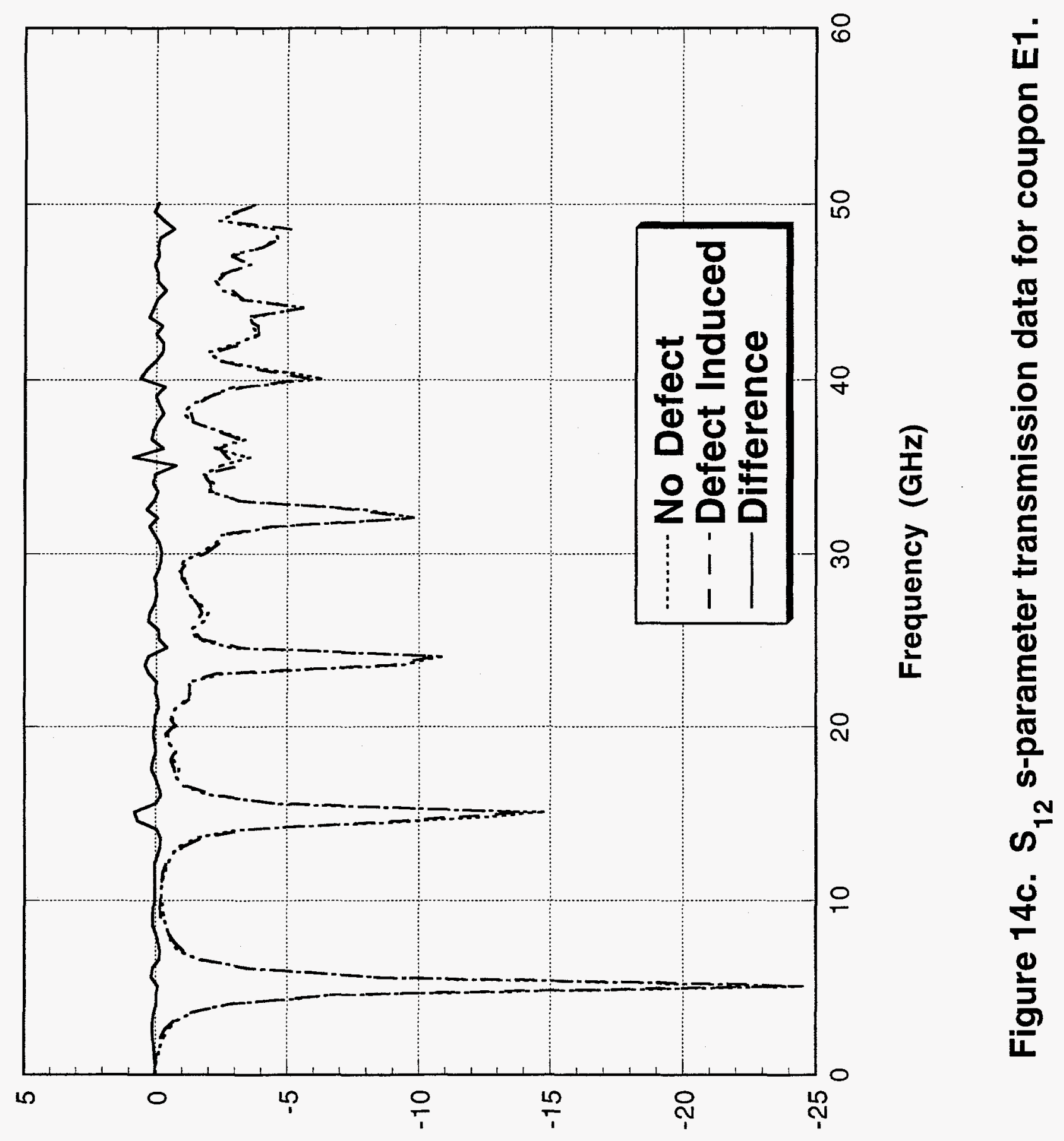

(gp) әpnц!u6ew 


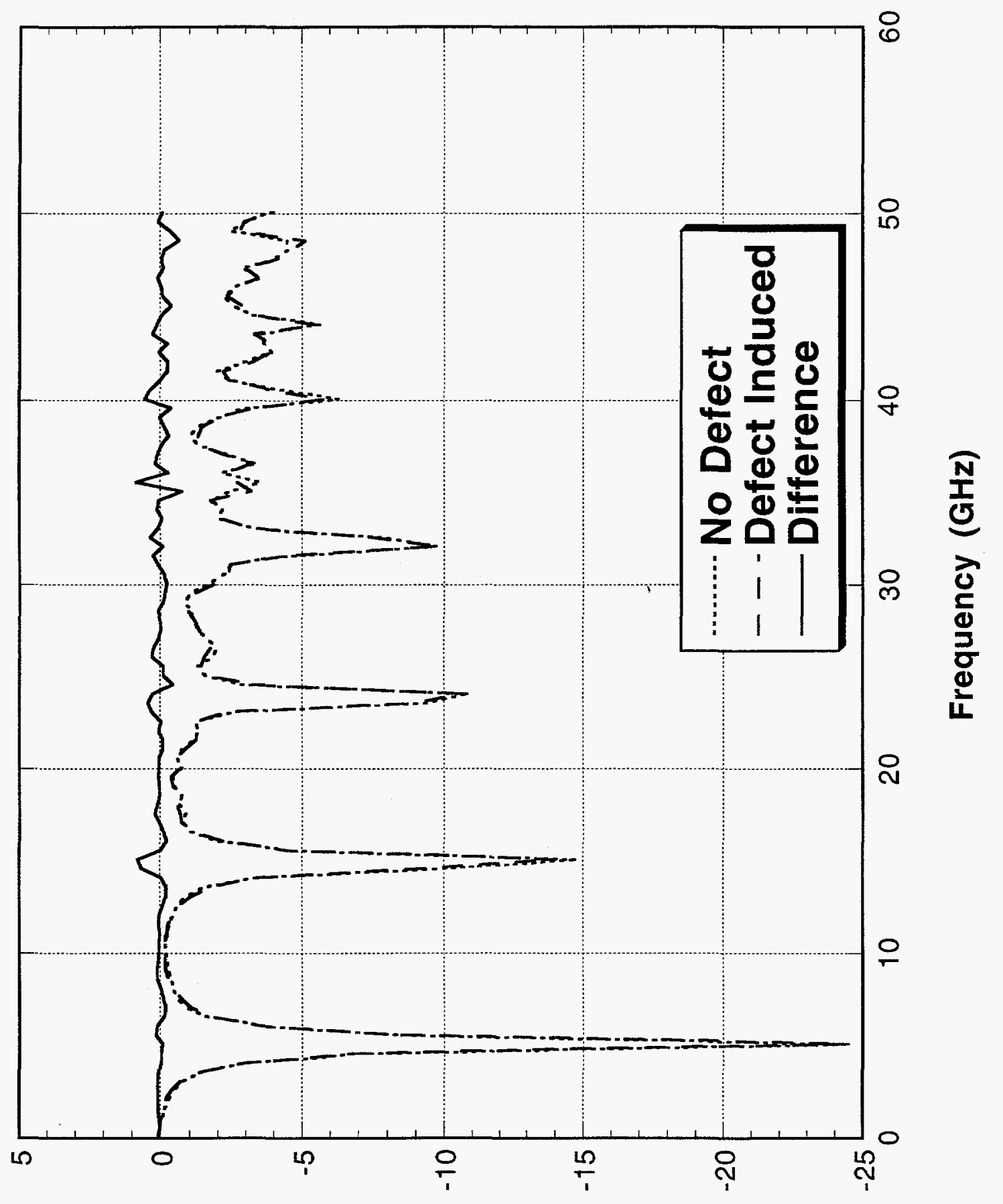

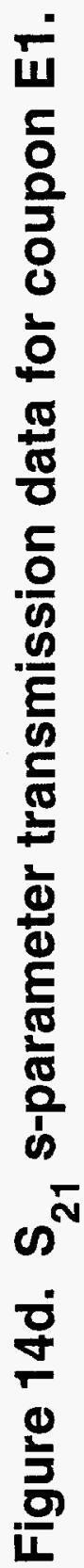

(gp) әрnұ!̣u6ew 


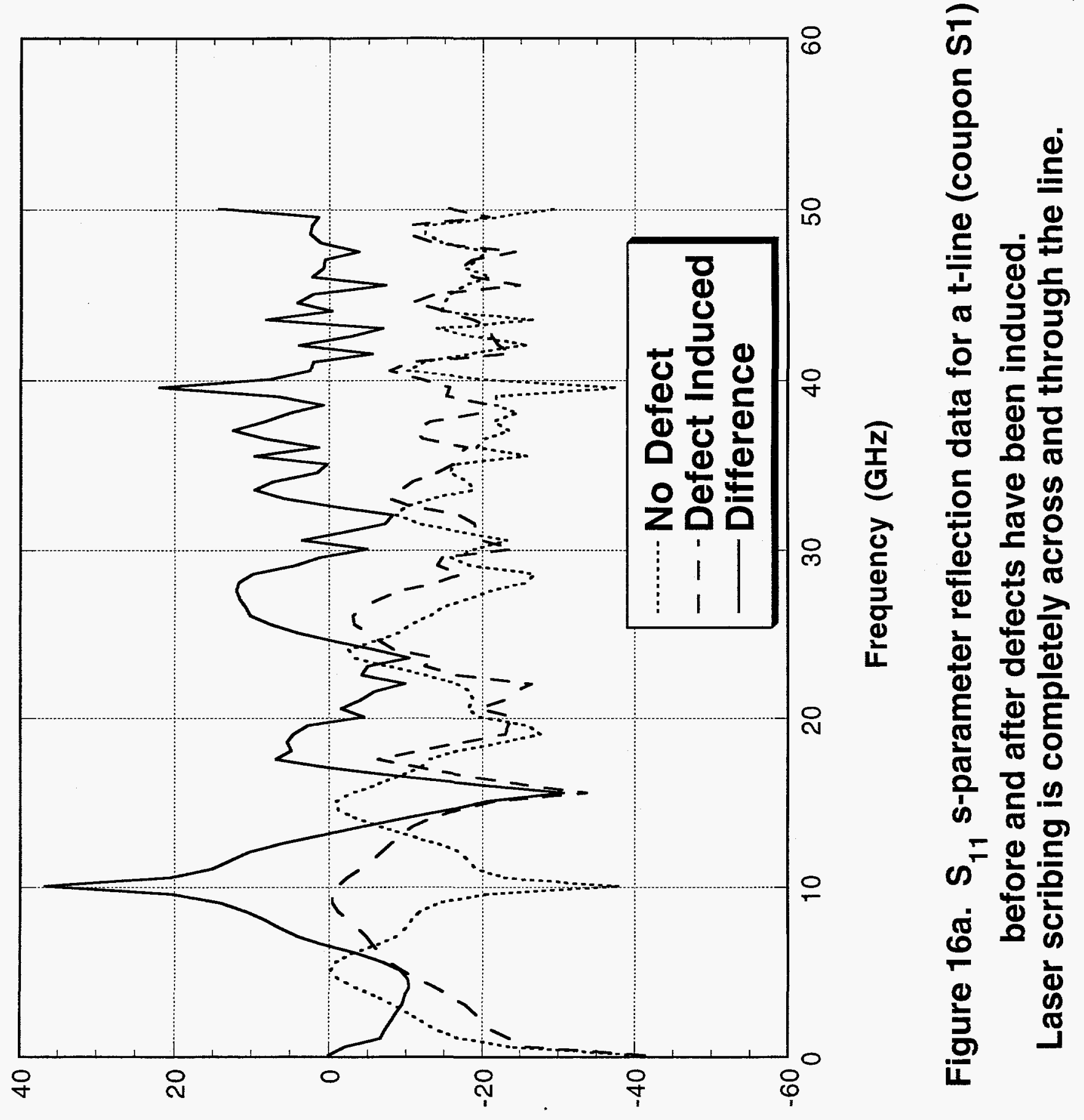

(gp) әрnџ!ฺбеw 


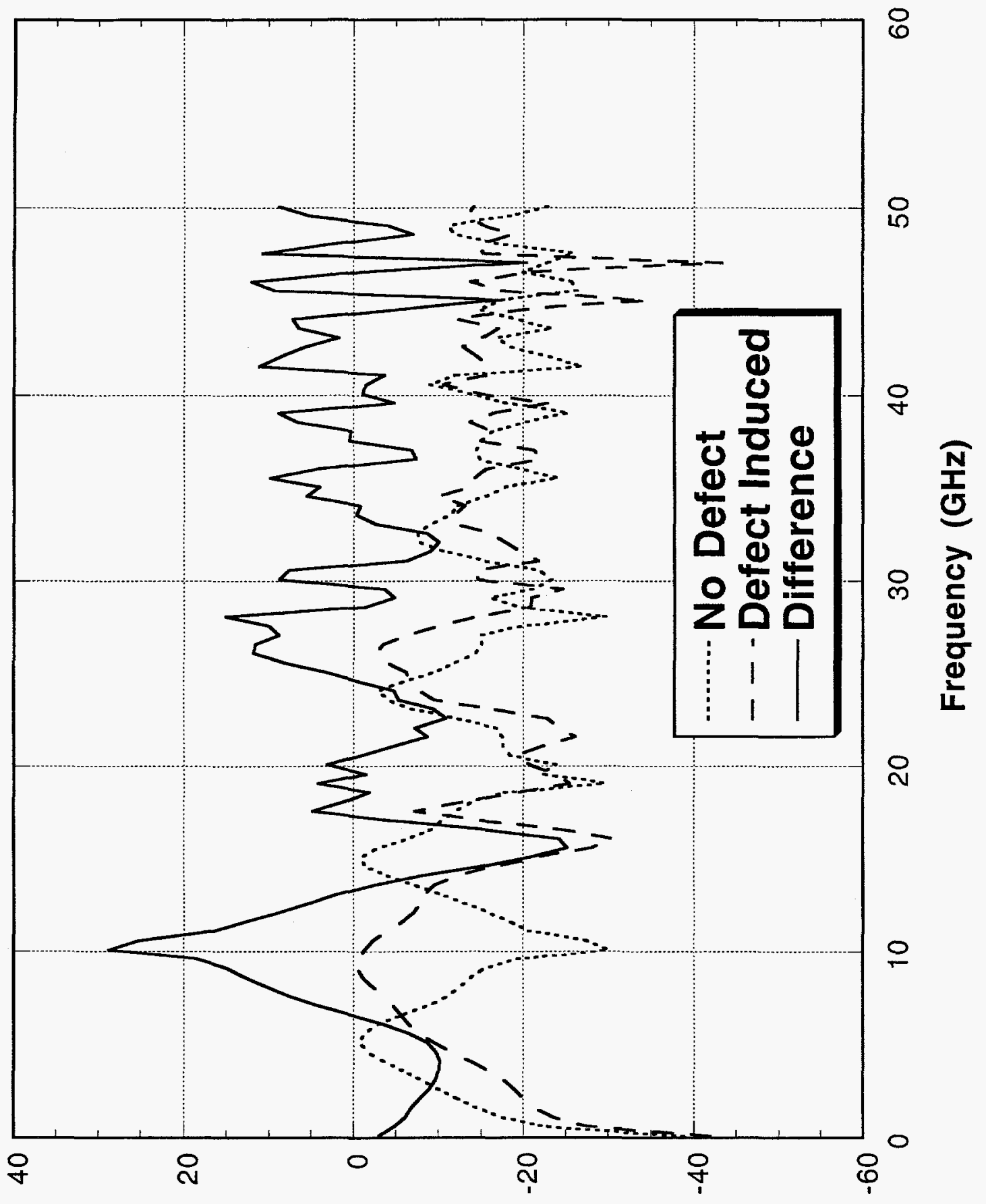

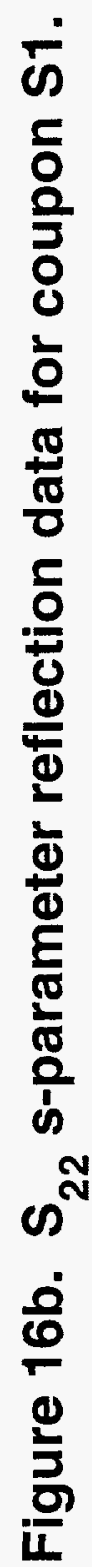

(ap) әpnџ!uбew 


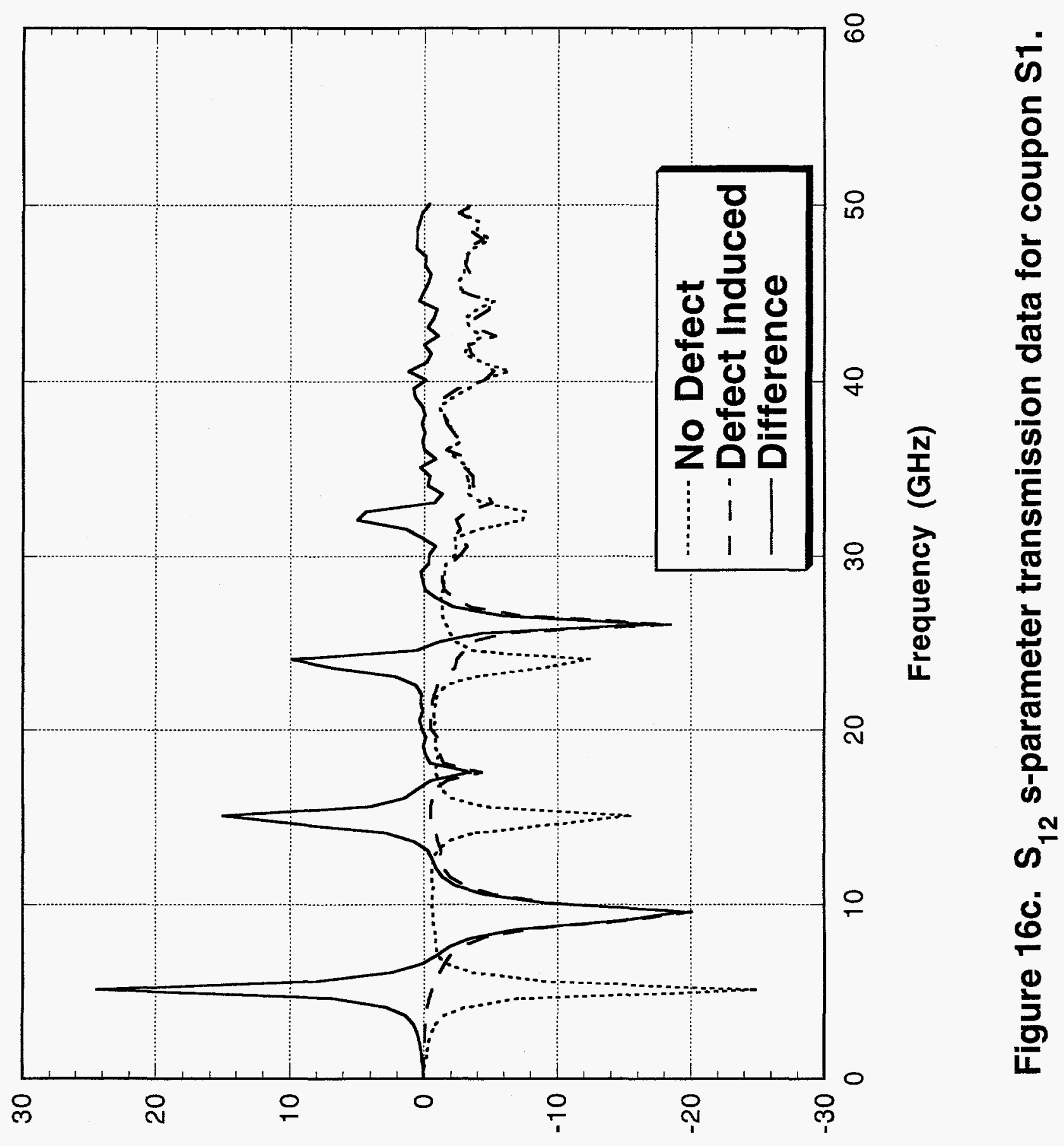

(gp) әрnұ!u6ew 


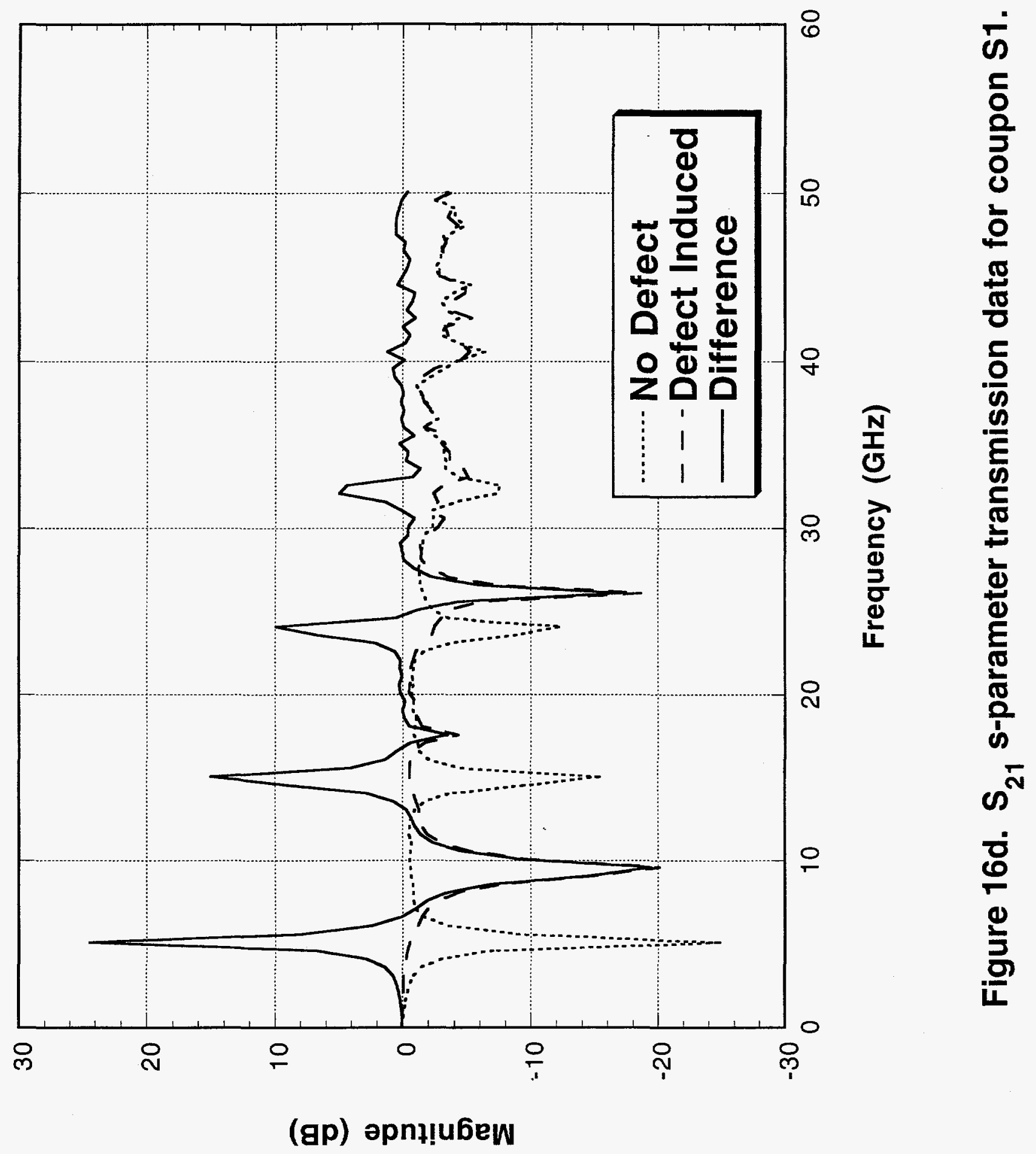


Internal Distribution:

\begin{tabular}{lll}
1 & 1435 & A. K. Hays, 1800 \\
1 & 1434 & J. L. Jellison, 1803 \\
1 & 1434 & Gordon Pike, 1802 \\
1 & 0342 & R. Salzbrenner, 1805 \\
1 & 0367 & Brian Damkroger, 1833 \\
10 & 1411 & Cynthia Hernandez, 1833 \\
10 & 1411 & F. Michael Hosking, 1833 \\
1 & 1411 & Jerome Rejent, 1833 \\
1 & 1411 & Paul Vianco, 1833 \\
1 & 1351 & Ken Holley, 3513 \\
1 & 1351 & W. R. Dawes, 3513 \\
1 & 0874 & David W. Palmer, 1716 \\
1 & 0874 & Charlie Sandoval, 1716 \\
5 & 0746 & David Robinson, 6411 \\
1 & 0746 & Robert Cranwell, 6411 \\
5 & 0829 & Brian Rutherford, 12323 \\
1 & 0829 & Kathleen V. Diegert, 12323 \\
5 & 0959 & Fernando Uribe, 1471 \\
1 & 0959 & Robert Poole, 1471 \\
1 & 9018 & Central Technical Files, 8940-2 \\
2 & 0899 & Technical Library, 4916 \\
1 & 0619 & Review \& Approval Desk, 15102 \\
& & For DoE/OSTI \\
& & \\
\hline & &
\end{tabular}


External Distribution:

1 Dr. Samuel G. White, Jr.

Dean - College of Engineering

Olin Engineering Building

Hampton University

Hampton, VA 23668

1 Dr. Alphonso C. Smith

Chairman - EE Department

Olin Engineering Building

Hampton University

Hampton, VA 23668

1 Dr. Ganiyu Hanidu

Applied Simulation \& Modeling

Motorola, Inc.

1303 East Algonquin Rd.

IL 01/Annex 2

Schaumburg, IL 60196

3. Christopher C. Green

3053 N. Longhorn Dr.

Tucson, AZ 85749
1 Dr. Adebisi O. Oladipupo

College of Engineering

Olin Engineering Building

Hampton University

Hampton, VA 23668

1 Lareina Adams Moore

HHT 1-1 CAV

CMR-401 Box 372

APO AE 09076

1 Dr. Mohammed Rachedine

Applied Simulation \& Modeling

Motorola, Inc.

1303 East Algonquin Rd.

IL 01/Annex 2

Schaumburg, IL 60196 